\title{
A COMPUTATIONAL INVESTIGATION ON THE REDUCING LATERAL VIBRATION OF ROTORS WITH ROLLING-ELEMENT BEARINGS PASSING THROUGH CRITICAL SPEEDS BY MEANS OF TUNING THE STIFFNESS OF THE SYSTEM SUPPORTS
}

\author{
Authors: \\ Jaroslav ZAPOMĚL ${ }^{*}$ \\ Institute of Thermomechanics, Czech Academy of Sciences \\ branch at VSB - Technical University of Ostrava \\ Centre of Intelligent Systems and Structures \\ 17. listopadu 15 \\ Ostrava - Poruba \\ 70833 \\ Czech Republic \\ E-mail: jaroslav.zapomel@vsb.cz \\ Tel.: +420 59732 3267, Fax.: +420 597321287

\section{Petr FERFECKI} \\ Institute of Thermomechanics, Czech Academy of Sciences \\ branch at VSB - Technical University of Ostrava \\ Centre of Intelligent Systems and Structures \\ 17. listopadu 15 \\ Ostrava - Poruba \\ 70833 \\ Czech Republic \\ E-mail: petr.ferfecki@vsb.cz \\ Tel.: +420 59732 9359, Fax.: +420 597321228
}

* - corresponding author 


\begin{abstract}
Since there are manufacturing and assembling inaccuracies rotors are always slightly imbalanced. Their rapid angular acceleration leads to an increase in the magnitude of the tangential component of the imbalance forces. The slow acceleration enables the development of an almost steady state vibration. In both cases the amplitude of their oscillation is high. The frequency tuning achieved by changing the stiffness of the rotor supports represents one approach to its attenuation. Stiffness decreases shortly before reaching the critical speed, and after crossover it, the stiffness increases again. As almost all publications and computer procedures from the field of rotor dynamics deal only with the case when the rotor turns at a constant angular speed, derivation of the equations of motion of the rotor rotating at variable velocities and investigation of the operating conditions and individual parameters of the supports on the vibration of the rotor passing critical speeds represent the fully new contribution of this paper. The critical revolutions are determined from the Campbell diagram. To solve the equations of motion the Newmark method has been proposed and tested.
\end{abstract}

Keywords: accelerating rotors, lateral vibration, critical speeds, equations of motion, tuning of the stiffness of the rotor supports, Newmark method, finite element method

\title{
1 Introduction
}


The rotor systems consist of two principal components: a rotor and a stationary part. Because of their high loading capacity and high stiffness rolling-element bearings are often used for their coupling.

Rotors of rotating machines are always slightly imbalanced due to manufacturing and assembling inaccuracies. Especially if they run over the critical speeds, the imbalance produces a vibration of a large amplitude. Rapid angular acceleration leads to an increase in the magnitude of the tangential component of the imbalance forces. Slow acceleration enables the development of an almost steady state vibration. In both cases the amplitudes of the induced oscillations are high.

The principal aim of this article is to contribute to the development of computational procedures for an efficient analysis of the lateral vibration of rotors supported by rollingelement bearings. The particular attention is paid to the case when the rotor increases or decreases the speed of its rotation when passing critical revolutions and to the attenuation of its vibration by frequency tuning. This manipulation requires a change in the stiffness of the rotor supports when it rotates at a speed close to its critical revolutions. The experience showed that efficiency of this manipulation depended not only on the magnitude and rate of the stiffness change but also on the moment of time when the tuning started before reaching the critical rotational speeds. From the technological point of view this enables the use of a motor of a lower rated power. There are several design possibilities to change the stiffness of the supports. A mechanical one based on the change of the length of an elastic spring is described in [1]. The controlled change in the stiffness of a rotor by a bearing movable in the axial direction is reported in [2]. For investigation of the elimination of the rotor unbalance the authors used only a simple rotor of a Jeffcott type. Another possibility how to change the stiffness of the structure supports is represented by piezoelectric devices. For example, the stiffness of a lead-zirconate-titanate piezoceramic actuator with short-circuited electrodes on its faces is smaller by about $20-40 \%$ than in the case when the opposite faces of the actuator are not electrically connected. Further possibility is usage of smart memory metals [3]. The spring elements supporting the rotor are made of shape memory alloys and the change in their stiffness is accomplished by their heating or cooling.

To analyze this problem and to propose the optimal speed of passing the critical revolutions a computer modelling method can be used. Unfortunately, many publications and computer procedures from the field of rotor dynamics are related only to the case when the rotor turns at a constant angular speed. Moreover, if the discs or rotors turning at variable speed are investigated, the forms of the equations of motion derived by different authors slightly differ and the differences depend on the method used for their derivation. The equations of motion of a symmetric rotating disc having four degrees of freedom have been derived in [4]. Using the assumption of small displacements and rotations, the authors simplified Euler's dynamical equations by neglecting small terms of the second and higher orders. But the resulting relationships are referred again to a disc rotating only at a constant angular speed. In [5] the equations of motion for a Stodola rotor are derived by means of the impulse theorems. Even if they are related only to constant speed of the rotor rotation, they can be easily extended for the case when the rotor turns with variable revolutions. Then the terms of inertia moment for rotor spin motion would occur in both moment equations. Such equations of a flexibly supported disc performing a spherical movement with variable speed are used in [6-9]. The system has two degrees of freedom and therefore its vibration is governed by two equations. In [10] there are derived the motion equations of a disc and of a shaft element. For their derivation the Lagrange's equations of the second kind were used. The resulting equations of 
motion are asymmetric because only one moment equation contains the inertia term of the spin motion of the disc or of the shaft element. Moreover, if the rotations about the axes of the reference frame used by the authors were performed in reverse order, the inertia term would appear in the other moment equation which because of validity of the principle of superposition is not acceptable. The equations of motion referred to a rigid disc rotating at variable speed and derived by means of the Lagrange equations of the second kind can be found also in [11]. Both resulting moment equations of motion do not contain any inertia terms corresponding to the spin motion of the disc. This form of the equations of motion was used also by some other authors, e.g. [12]. As evident from this survey, it is desirable to deal with the derivation of the governing equations of flexible rotors turning with variable speed in more details and to discuss the mentioned differences.

In the mathematical models the shaft is usually represented by a beam-like body that is discretized into finite elements and the discs are considered to be thin and rigid. Derivation of the mass, stiffness, and gyroscopic matrices of the disc and of the shaft elements has been performed by Nelson [13] but now it can be found also in a number of further publications, e.g. in [14]. Implementation of the internal damping into the shaft element was done by Zorzi and Nelson in [15]. But all these equations of motion are valid only if the rotor rotates at a constant angular speed. The rolling-element bearings are distinguished by their high stiffness and almost no damping. They are implemented into mathematical models by means of linear or non-linear isotropic or orthotropic springs and the damping elements that produce forces in two mutually perpendicular directions. A determination of the stiffness and damping parameters of ball and roller bearings with no pre-stress and zero clearances between the rolling elements and the races is given in [16].

The problem of attenuation of rotors passing critical speeds by tuning their support stiffness has been studied since approximately the 60-ties of the 20th century. Irretier and Leul [17] investigated a single-degree-of-freedom system with no internal damping and gyroscopic effects. The angular acceleration of the rotor was constant and the change of the system natural frequency was linear with respect to time. Nagaya et al. [3] studied the undamped multi stepped rotor with one disc. The gyroscopic effect was taken into account and the shaft deflection was described by an analytical function. Ballo and Chmurny [18-20] analysed the influence of the magnitude and rate of decrease of the shaft support stiffness and of the moment of time when this manipulation should start on reducing the rotor vibration amplitude. Their mathematical model was very simple (no damping, no gyroscopes effects, two degrees of freedom, constant cross section of the shaft, no discs) and they used a small parameter method. Wauer and Suherman [21] focused their work on the study of the influence of the change in the supports stiffness on the rotor lateral vibration and on the driving moment needed for crossing the resonance speed. Their rotor was represented by a slender bar of a constant circular cross section. Millsaps and Reed [22] dealt with lateral vibration of a Laval rotor passing the critical speeds with constant acceleration or deceleration. They analysed the effect of the rotor angular acceleration on amplitude of the induced vibration and on fluctuation of the kinetic energy related to the whirl and spin motions of the rotor.

The principal contribution of the presented article consists in deriving the equations of motion for a flexible rotor with rigid discs rotating at a variable angular velocity utilizing the impulse theorems for this purpose and the principal of the virtual work and development of an efficient procedure for investigation of the attenuation of the amplitude of rotor vibration passing the critical speed by a change in the stiffness of the shaft supports. The critical revolutions are determined from the Campbell diagram, explained e.g. in [5, 16 and 23]. For 
solving the motion equations of the whole rotor system the Newmark method has been chosen. Applicability of the developed approach was tested by means of computer simulations.

\section{The equation of motion of a rigid disc}

In the proposed mathematical model it is assumed that (i) the disc is a thin, rigid, axisymmetric body, (ii) the middle plane of the disc is perpendicular to the centre line of the shaft, (iii) the force transmission between the disc and the shaft is accomplished at the point of intersection of the middle plane of the disc and the centre line of the shaft, (iv) the centre of gravity of the disc finds itself in its middle plane and is slightly displaced from the shaft centre line, and (v) the displacements and rotations of the disc are small.

Such a disc has four degrees of freedom. Its current position is defined by the position of its point $\mathrm{H}$ lying in the intersection of the middle plane of the disc and the centre line of the shaft and by the rotation of the disc about two axes perpendicular to the shaft centre line. Three reference frames were adopted to describe the movement of the disc (Fig.1).

The fixed coordinate system Oxyz is introduced in such a way that axis $\mathrm{x}$ is identical with the undeformed centre line of the shaft. Origin $\mathrm{O}$ lies in the middle plane of the disc and in the undeformed state it is identical with point $\mathrm{H}$. Axes $\mathrm{y}$ and $\mathrm{z}$ go in origin $\mathrm{O}$ and are perpendicular to axis $\mathrm{x}$.

The coordinate system Tx'y'z' is chosen so that its origin $T$ is situated in the disc centre of the mass (gravity). It moves together with the disc but its coordinate axes x', y', z' remain parallel with axes $x, y, z$ of the fixed reference frame (Tx'y'z' performs only a translation motion).

The third coordinate system $T \xi \eta \zeta$ has its origin in the centre of gravity of the disc and axes $\xi$, $\eta, \zeta$ are the principal axes of inertia of the disc. This system translates together with the centre of gravity and performs small rotations about axes y' and z'. These angles of rotation are equal to the rotation angles of the disc's middle plane about the coordinate axes $\mathrm{y}$ and $\mathrm{z}$. The direction of axis $\xi$ is close to axis $x^{\prime}$ and because the disc is axisymmetric axes $\eta$ and $\zeta$ remain the principal axes of inertia at each of its position. 

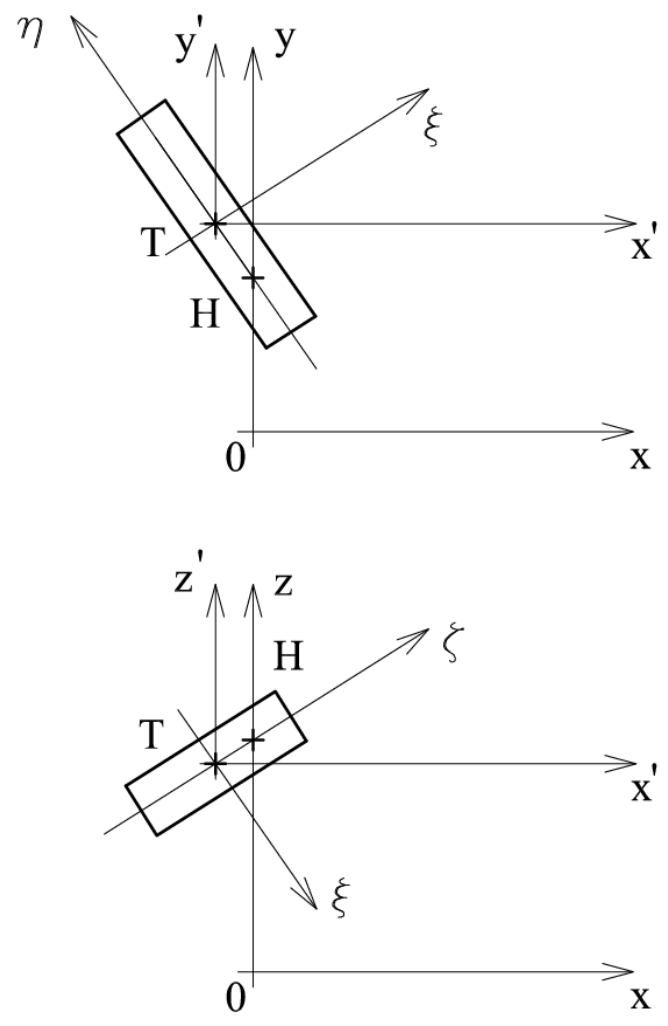

Fig.1 Reference frames of the disc

Assuming small displacements the disc performs the motion composed of a translation one given by movement of the disc centre of gravity $\mathrm{T}$ and of a spherical motion about its centre of gravity.

Position of the disc is then defined by displacements of the disc centre of gravity $\mathrm{y}_{\mathrm{T}}$ and $\mathrm{z}_{\mathrm{T}}$, by two rotations $\varphi_{\mathrm{y}}$ and $\varphi_{\mathrm{z}}$ of the middle plane of the disc about axes $\mathrm{y}$ and $\mathrm{z}$ of the fixed reference frame, and by angle $\varphi_{\mathrm{T}}$ (Fig.2). Since the deflection of the shaft point $H$ moves in the perpendicular direction to the shaft centre line. Due to small displacements it holds

$$
\begin{aligned}
& \mathrm{y}_{\mathrm{T}}=\mathrm{y}+\mathrm{e}_{\mathrm{T}} \cos \varphi_{\mathrm{T}} \\
& \mathrm{z}_{\mathrm{T}}=\mathrm{z}+\mathrm{e}_{\mathrm{T}} \sin \varphi_{\mathrm{T}}
\end{aligned}
$$

$\mathrm{y}, \mathrm{z}$ are displacements of the disc centre $\mathrm{H}$ in the coordinate system $\mathrm{Oxyz}, \mathrm{e}_{\mathrm{T}}$ is the eccentricity of the disc centre of the mass (the centre of gravity), $\varphi_{\mathrm{T}}$ is the directional angle of the half-line connecting the disc centre $\mathrm{H}$ with the centre of mass $\mathrm{T}$. 


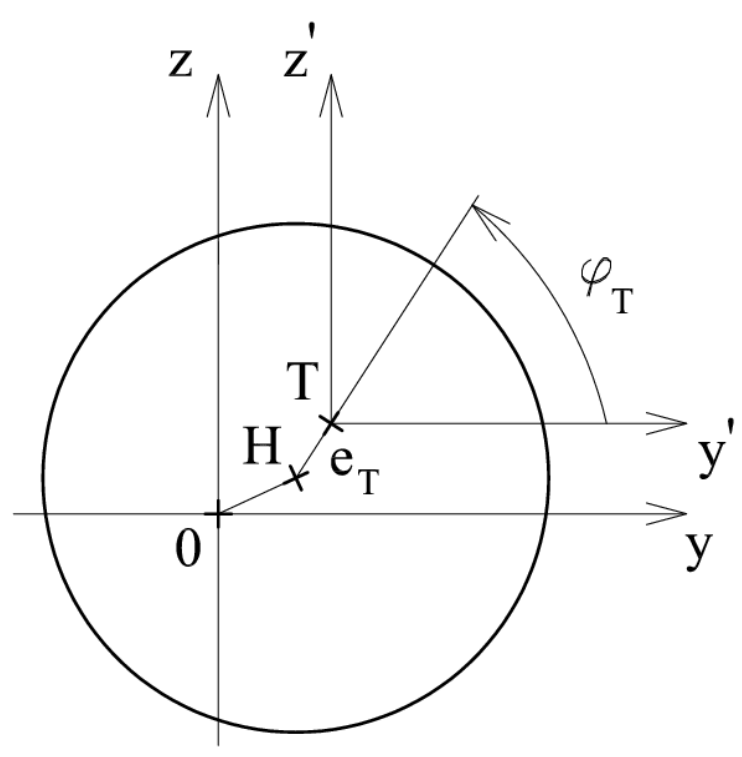

Fig.2 Reference frames of the disc and definition of the angular position of the rotor

The disc performs a spatial motion that is composed of the translation one defined by the movement of its centre of the mass and of a spherical motion around the centre of the mass. According to the impulse theorems the motion of the disc is governed by the following equations

$$
\begin{aligned}
& \frac{\mathrm{d}}{\mathrm{dt}}\left(\mathrm{m}_{\mathrm{D}} \dot{\mathrm{y}}_{\mathrm{T}}\right)=\mathrm{F}_{\mathrm{Cy}} \\
& \frac{\mathrm{d}}{\mathrm{dt}}\left(\mathrm{m}_{\mathrm{D}} \dot{\mathrm{z}}_{\mathrm{T}}\right)=\mathrm{F}_{\mathrm{Cz}} \\
& \frac{\mathrm{dL}}{\mathrm{dt}}=\mathrm{M}_{\mathrm{TCy}} \\
& \frac{\mathrm{dL}}{\mathrm{Tz}}=\mathrm{M}_{\mathrm{TCz}}
\end{aligned}
$$

where $\mathrm{m}_{\mathrm{D}}$ is mass of the disc, $\dot{\mathrm{y}}_{\mathrm{T}}, \dot{\mathrm{z}}_{\mathrm{T}}$ are the velocity components of the disc centre of the mass in the $\mathrm{y}$ and $\mathrm{z}$ directions, $\mathrm{F}_{\mathrm{Cy}}, \mathrm{F}_{\mathrm{Cz}}$ are the $\mathrm{y}$ and $\mathrm{z}$ components of the resulting force of the applied and constraint ones acting on the liberated disc, $\mathrm{L}_{\mathrm{Ty}}, \mathrm{L}_{\mathrm{Tz}}$ are the $\mathrm{y}$ and $\mathrm{z}$ components of the moment of momentum of the disc relative to its centre of the mass, $\mathbf{M}_{\mathrm{TCy}}, \mathrm{M}_{\mathrm{TCz}}$ are the $\mathrm{y}$ and $\mathrm{z}$ components of the resulting moment of the applied and constraint forces acting on the liberated disc, and $t$ is the time.

Let the angular velocity and angular acceleration of the disc rotation be noted

$$
\omega=\dot{\varphi}_{\mathrm{T}} \quad, \quad \varepsilon=\ddot{\varphi}_{\mathrm{T}}
$$

Dots ( $\left.{ }^{*}\right),\left({ }^{*}\right)$ denote the first and second differentiation with respect to time in (7) and in all the subsequent expressions.

Performing the differentiation of (3), (4) with respect to time taking into account (1), (2) and (7) one obtains 


$$
\begin{aligned}
& \mathrm{m}_{\mathrm{D}} \ddot{\mathrm{y}}=\mathrm{m}_{\mathrm{D}} \mathrm{e}_{\mathrm{T}} \omega^{2} \cos \varphi_{\mathrm{T}}+\mathrm{m}_{\mathrm{D}} \mathrm{e}_{\mathrm{T}} \varepsilon \sin \varphi_{\mathrm{T}}+\mathrm{F}_{\mathrm{Cy}} \\
& \mathrm{m}_{\mathrm{D}} \ddot{\mathrm{z}}=\mathrm{m}_{\mathrm{D}} \mathrm{e}_{\mathrm{T}} \omega^{2} \sin \varphi_{\mathrm{T}}-\mathrm{m}_{\mathrm{D}} \mathrm{e}_{\mathrm{T}} \varepsilon \cos \varphi_{\mathrm{T}}+\mathrm{F}_{\mathrm{Cz}}
\end{aligned}
$$

$\ddot{y}, \ddot{z}$ are acceleration components of the disc centre (point $H$ ).

The disc is axial symmetric and therefore $\xi, \eta, \zeta$ are its principal axes of inertia at any position of the disc. Because the displacements and rotations are assumed to be small, components of the disc moment of momentum can be expressed (Fig.3)

$$
\begin{aligned}
& \mathrm{L}_{\mathrm{Ty}}=\mathrm{J}_{\mathrm{D}} \dot{\varphi}_{\mathrm{y}}+\mathrm{J}_{\mathrm{P}} \omega \varphi_{\mathrm{z}} \\
& \mathrm{L}_{\mathrm{Tz}}=\mathrm{J}_{\mathrm{D}} \dot{\varphi}_{\mathrm{z}}-\mathrm{J}_{\mathrm{P}} \omega \varphi_{\mathrm{y}}
\end{aligned}
$$

$\mathrm{J}_{\mathrm{D}}$ and $\mathrm{J}_{\mathrm{P}}$ are the disc inertia moments relative to its diametrical axis and to the axis of its rotation respectively.
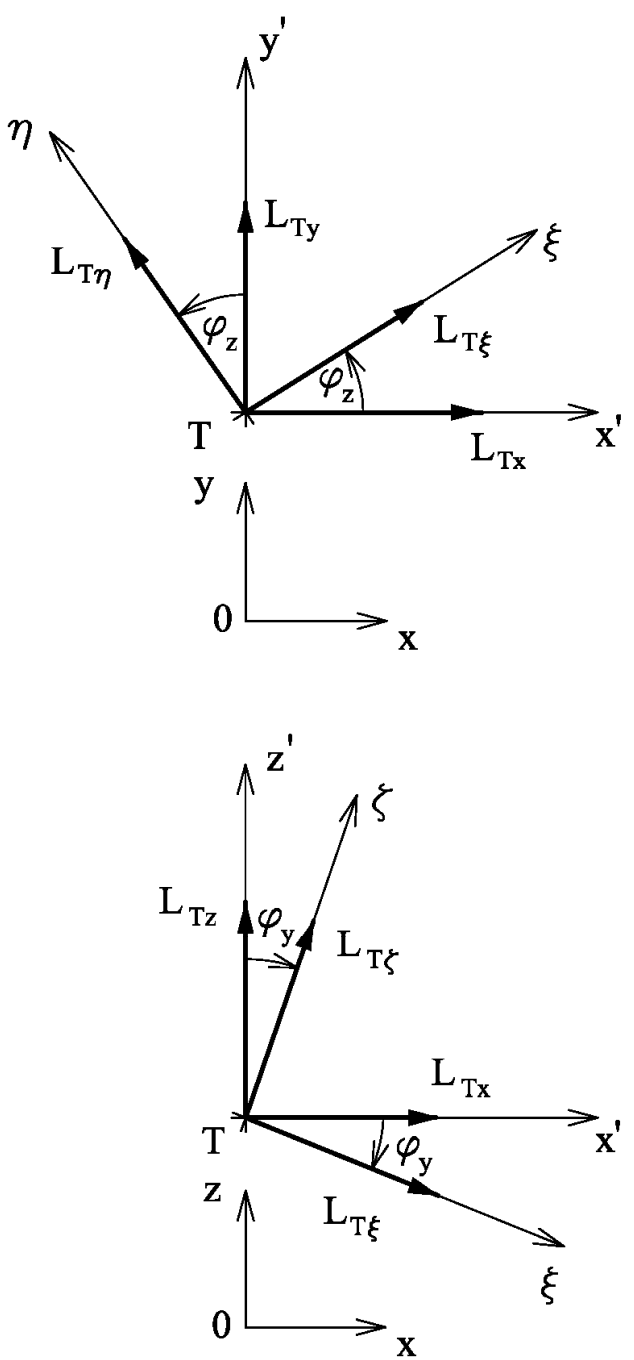

Fig.3 Transformation of the moments of momentum of the disc

Differentiation of (10) and (11) with respect to time and making use of (5) and (6) give the equations of motion governing the spherical movement of the disc 


$$
\begin{aligned}
& \mathrm{J}_{\mathrm{D}} \ddot{\varphi}_{\mathrm{y}}+\mathrm{J}_{\mathrm{P}} \omega \dot{\varphi}_{\mathrm{z}}+\mathrm{J}_{\mathrm{P}} \varepsilon \varphi_{\mathrm{z}}=\mathrm{M}_{\mathrm{TCy}} \\
& \mathrm{J}_{\mathrm{D}} \ddot{\varphi}_{\mathrm{z}}-\mathrm{J}_{\mathrm{P}} \omega \dot{\varphi}_{\mathrm{y}}-\mathrm{J}_{\mathrm{P}} \varepsilon \varphi_{\mathrm{y}}=\mathrm{M}_{\mathrm{TCz}}
\end{aligned}
$$

$\dot{\varphi}_{\mathrm{y}}, \dot{\varphi}_{\mathrm{z}}, \ddot{\varphi}_{\mathrm{y}}, \ddot{\varphi}_{\mathrm{z}}$ are the angular velocities and accelerations of rotation of the disc middle plane (of the shaft cross section to which the disc belongs) about axes $\mathrm{y}$ and $\mathrm{z}$.

As eccentricity of the disc is small, moments of forces acting on the disc can be related to point $\mathrm{O}$ instead of to point $\mathrm{T}$ (point $\mathrm{O}$ is situated on the undeformed centre line of the shaft).

Assuming that damping of the disc is viscous, the equations of motion of the disc (8), (9), (12) and (13) can be rewritten in a matrix form

$$
\mathbf{M}_{\mathrm{DE}} \ddot{\mathbf{x}}_{\mathrm{DE}}+\left(\mathbf{B}_{\mathrm{DE}}+\omega \mathbf{G}_{\mathrm{DE}}\right) \dot{\mathbf{x}}_{\mathrm{DE}}+\varepsilon \mathbf{G}_{\mathrm{DE}} \mathbf{x}_{\mathrm{DE}}=\mathbf{f}_{\mathrm{DE}}
$$

$\mathbf{M}_{\mathrm{DE}}, \mathbf{G}_{\mathrm{DE}}, \mathbf{B}_{\mathrm{DE}}$ are the mass, gyroscopic, and external damping matrices of the disc, $\mathbf{f}_{\mathrm{DE}}$ is the vector of general forces (applied and constraint) acting on the liberated disc, $\mathbf{x}_{\mathrm{DE}}, \dot{\mathbf{x}}_{\mathrm{DE}}$ and $\ddot{\mathbf{x}}_{\mathrm{DE}}$ are the vectors of the disc general displacements, velocities and accelerations.

\section{The equation of motion of a shaft element}

The shaft element (Fig.4) is generalized as a beam one. It can be deformed by deflection in two mutually perpendicular planes and in addition it turns about its centre line. The shaft element is defined by two nodes and has eight degrees of freedom (displacements $y, z$ in directions $\mathrm{y}$ and $\mathrm{z}$, rotations $\varphi_{\mathrm{y}}, \varphi_{\mathrm{z}}$ about axes $\mathrm{y}$ and $\mathrm{z}$ at each node). Its parameters are denoted: $\mathrm{L}$ is the length of the element, $\mathrm{S}$ is the area of the cross section of the element, $\mathrm{J}_{\mathrm{SD}}$ and $\mathrm{J}_{\mathrm{SP}}$ are the diameter and axial quadratic moments of area of the element cross section, $\mathrm{E}$, $\rho, \eta_{\mathrm{V}}$ are the Young's modulus, density and coefficient of viscous damping of the element material respectively.

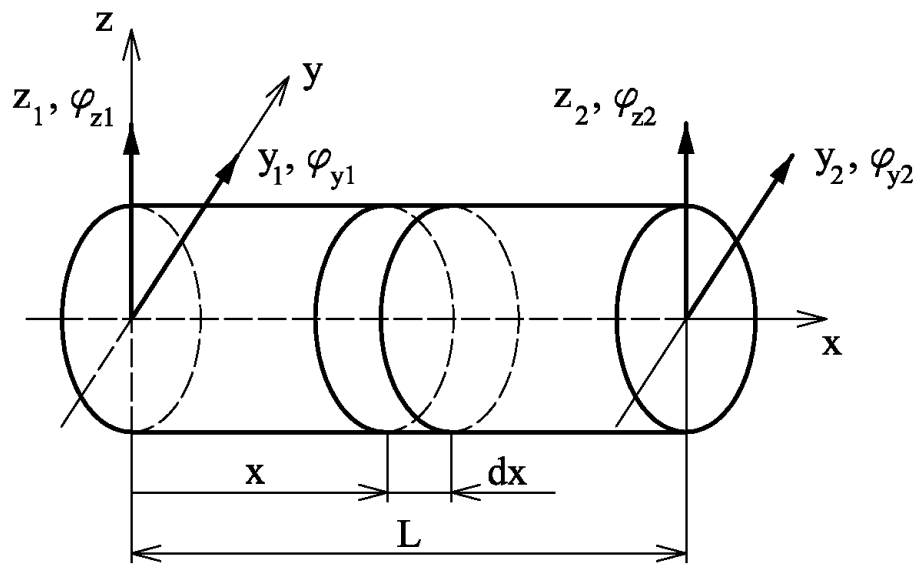

Fig.4 Shaft element

Deflection of the centre line of the element in the directions of axes $y$ and $z$ of the element reference frame are approximated by the polynomial shape functions 


$$
\begin{aligned}
& y=a_{0 y}+a_{1 y} x+a_{2 y} x^{2}+a_{3 y} x^{3} \\
& z=a_{0 z}+a_{1 z} x+a_{2 z} x^{2}+a_{3 z} x^{3}
\end{aligned}
$$

$\mathrm{x}$ is the $\mathrm{x}$-coordinate of the point on the centre line of the shaft element in the element reference frame, $\mathrm{y}, \mathrm{z}$ are the deflections (displacements) of the point on the shaft centre line in directions $y$ and $z$ and $a_{i y}$ and $a_{i z}$ are the coefficients of the shape function $(i=0,1,2,3)$.

Let the following column matrices be introduced

$$
\begin{gathered}
\mathbf{a}=\left[a_{0 y}, a_{1 y}, a_{2 y}, a_{3 y}, a_{0 z}, a_{1 z}, a_{2 z}, a_{3 z}\right]^{T} \\
\mathbf{p}_{y}(x)=\left[1, x, x^{2}, x^{3}, 0,0,0,0\right]^{T} \\
\mathbf{p}_{z}(x)=\left[0,0,0,0,1, x, x^{2}, x^{3}\right]^{T} \\
\mathbf{r}_{y}(x)=\left[0,1,2 x, 3 x^{2}, 0,0,0,0\right]^{T} \\
\mathbf{r}_{z}(x)=\left[0,0,0,0,0,1,2 x, 3 x^{2}\right]^{T}
\end{gathered}
$$

After expressing the coefficient vector a by means of the nodal deformation parameters

$$
\mathbf{a}=\mathbf{P}^{-1} \mathbf{x}_{\mathrm{HE}}
$$

where

$$
\begin{gathered}
\mathbf{x}_{\mathrm{HE}}=\left[\mathrm{y}_{1}, \mathrm{z}_{1}, \varphi_{\mathrm{y} 1}, \varphi_{\mathrm{z} 1}, \mathrm{y}_{2}, \mathrm{z}_{2}, \varphi_{\mathrm{y} 2}, \varphi_{\mathrm{z} 2}\right]^{\mathrm{T}} \\
\mathbf{P}=\left[\mathbf{p}_{\mathrm{y}}(0), \mathbf{p}_{\mathrm{z}}(0),-\mathbf{r}_{\mathrm{y}}(0), \mathbf{r}_{\mathrm{z}}(0), \mathbf{p}_{\mathrm{y}}(\mathrm{L}), \mathbf{p}_{\mathrm{z}}(\mathrm{L}),-\mathbf{r}_{\mathrm{y}}(\mathrm{L}), \mathbf{r}_{\mathrm{z}}(\mathrm{L})\right]^{\mathrm{T}}
\end{gathered}
$$

the relations for the displacements and rotations of any cross section of the shaft element take the form

$$
\begin{aligned}
& \mathrm{y}(\mathrm{x})=\mathbf{p}_{\mathrm{y}}^{\mathrm{T}}(\mathrm{x}) \mathbf{P}^{-1} \mathbf{x}_{\mathrm{HE}} \\
& \mathrm{z}(\mathrm{x})=\mathbf{p}_{\mathrm{z}}^{\mathrm{T}}(\mathrm{x}) \mathbf{P}^{-1} \mathbf{x}_{\mathrm{HE}} \\
& \varphi_{\mathrm{y}}(\mathrm{x})=-\mathbf{r}_{\mathrm{z}}^{\mathrm{T}}(\mathrm{x}) \mathbf{P}^{-1} \mathbf{x}_{\mathrm{HE}} \\
& \varphi_{\mathrm{z}}(\mathrm{x})=\mathbf{r}_{\mathrm{y}}^{\mathrm{T}}(\mathrm{x}) \mathbf{P}^{-1} \mathbf{x}_{\mathrm{HE}}
\end{aligned}
$$

$\mathbf{x}_{\mathrm{HE}}$ is the vector of general displacements of the shaft element, $\mathrm{y}_{1}, \mathrm{z}_{1}$ are the displacements in $\mathrm{y}, \mathrm{z}$ directions at node $1, \varphi_{\mathrm{y} 1}, \varphi_{\mathrm{z} 1}$ are the rotations about axes $\mathrm{y}$ and $\mathrm{z}$ at node $1, \mathrm{y}_{2}, \mathrm{z}_{2}$ are the displacements in directions $\mathrm{y}$ and $\mathrm{z}$ at node 2 , and $\varphi_{\mathrm{y} 2}, \varphi_{\mathrm{z} 2}$ are the rotations about axes $\mathrm{y}, \mathrm{z}$ at node 2 .

To derive the equation of motion of the shaft element a principal of virtual work will be used. According to it the sum of virtual works of all working forces and those of inertia acting on the liberated element are equal to zero

$$
\delta \mathrm{A}_{\mathrm{WF}}+\delta \mathrm{A}_{\mathrm{IF}}=0
$$

$\delta A_{\mathrm{WF}}$ is the virtual work of the applied and constraint forces and moments and the internal forces produced by material elasticity and internal and external damping acting on the 
liberated shaft element. Both material and external damping is assumed to be of a viscous kind. $\delta \mathrm{A}_{\mathrm{IF}}$ is the virtual work produced by inertia forces and moments of the element.

The virtual work $\delta \mathrm{A}_{\mathrm{WF}}$ is given by the relation

$$
\delta \mathrm{A}_{\mathrm{WF}}=\delta \mathbf{x}_{\mathrm{HE}}^{\mathrm{T}}\left[\mathbf{f}_{\mathrm{HE}}-\left(\mathbf{B}_{\mathrm{HE}}+\eta_{\mathrm{V}} \mathbf{K}_{\mathrm{HE}}\right) \dot{\mathbf{x}}_{\mathrm{HE}}-\left(\mathbf{K}_{\mathrm{HE}}+\omega \mathbf{K}_{\mathrm{CHE}}\right) \mathbf{x}_{\mathrm{HE}}\right]
$$

$\mathbf{K}_{\mathrm{HE}}, \mathbf{K}_{\mathrm{CHE}}, \mathbf{B}_{\mathrm{HE}}$ are the stiffness, circulation and external damping matrices of the shaft element, $\mathbf{f}_{\mathrm{HE}}$ is the vector of general forces (applied and constraint) acting on the liberated element and $\eta_{\mathrm{V}}$ is the viscous damping coefficient of the element material. The individual matrices in (30) have been derived e.g. in $[13,15]$ and now they can be found in a number of further publications as in [10] or [24]. The material damping of the shaft is assumed to be viscous and therefore it depends only on the rate of the rotor deflection and on the speed of its rotation, not on its acceleration.

For the purpose of determining the virtual work of inertia forces a small cylinder of an infinitesimal thickness is specified by two section planes perpendicular to the center line of the shaft (Fig.4). This cylinder represents an infinitely thin circular disc. Moreover, it is assumed that its centre of the mass is slightly shifted from the shaft element centre line.

Utilizing relationships (8) and (9) components of the elementary inertia force of the infinitesimally thin disc $\mathrm{F}_{\mathrm{sy}}, \mathrm{F}_{\mathrm{sz}}$ can be expressed

$$
\begin{aligned}
& \mathrm{dF}_{\mathrm{Sy}}=-\ddot{y}(\mathrm{x}) \mathrm{dm}+\mathrm{e}_{\mathrm{T}}(\mathrm{x}) \omega^{2} \cos \varphi_{\mathrm{T}}(\mathrm{x}) \mathrm{dm}+\mathrm{e}_{\mathrm{T}}(\mathrm{x}) \varepsilon \sin \varphi_{\mathrm{T}}(\mathrm{x}) \mathrm{dm} \\
& \mathrm{dF}_{\mathrm{Sz}}=-\ddot{z}(\mathrm{x}) \mathrm{dm}+\mathrm{e}_{\mathrm{T}}(\mathrm{x}) \omega^{2} \sin \varphi_{\mathrm{T}}(\mathrm{x}) \mathrm{dm}-\mathrm{e}_{\mathrm{T}}(\mathrm{x}) \varepsilon \cos \varphi_{\mathrm{T}}(\mathrm{x}) \mathrm{dm}
\end{aligned}
$$

$\mathrm{dm}$ is the elementary mass of the infinitely thin shaft element. Displacements $\mathrm{y}, \mathrm{z}$ of the points on the shaft centre line, eccentricity $\mathrm{e}_{\mathrm{T}}$ of the centre of the mass of the infinitesimal element, and its position angle $\varphi_{\mathrm{T}}$ are functions of the axial coordinate $\mathrm{x}$.

Several simple manipulations employing relationships (12) and (13) yield the components of the inertia moment of the elementary disc

$$
\begin{aligned}
& \mathrm{dM}_{\mathrm{Sy}}=-\mathrm{dJ} \mathrm{J}_{\mathrm{D}} \ddot{\varphi}_{\mathrm{y}}(\mathrm{x})-\mathrm{dJ} \mathrm{J}_{\mathrm{P}} \omega \dot{\varphi}_{\mathrm{z}}(\mathrm{x})-\mathrm{dJ} \mathrm{J}_{\mathrm{P}} \varepsilon \varphi_{\mathrm{z}}(\mathrm{x}) \\
& \mathrm{dM}_{\mathrm{Sz}}=-\mathrm{dJ}_{\mathrm{D}} \ddot{\varphi}_{\mathrm{z}}(\mathrm{x})+\mathrm{dJ} \mathrm{J}_{\mathrm{P}} \omega \dot{\varphi}_{\mathrm{y}}(\mathrm{x})+\mathrm{dJ} \mathrm{J}_{\mathrm{P}} \varepsilon \varphi_{\mathrm{y}}(\mathrm{x})
\end{aligned}
$$

The mass and diameter and axial moments of inertia of the infinitely thin disc are given by the relations

$$
\begin{aligned}
\mathrm{dm} & =\rho(x) S(x) d x \\
d J_{D} & =\rho(x) J_{S D}(x) d x \\
d J_{P} & =\rho(x) J_{S P}(x) d x
\end{aligned}
$$

For the virtual work $\delta \mathrm{A}_{\mathrm{IF}}$ of inertia forces and moments of the elementary disc it holds

$$
\delta \mathrm{A}_{\mathrm{IF}}=\delta \mathrm{ydF} \mathrm{Sy}_{\mathrm{S}}+\delta \mathrm{dF}_{\mathrm{Sz}}+\delta \varphi_{\mathrm{y}} \mathrm{dM}_{\mathrm{Sy}}+\delta \varphi_{\mathrm{z}} \mathrm{dM}_{\mathrm{Sz}}
$$

The total virtual work of the inertia effects is obtained by the integration of (38) over the length of the whole shaft element. After substitution of (31) - (34) into (38) and utilizing (35) - (37) it holds 


$$
\begin{aligned}
\delta A_{I F}= & -\int_{0}^{\mathrm{L}} \delta \mathrm{y}(\mathrm{x})\left[\ddot{y}(\mathrm{x})-\mathrm{e}_{\mathrm{T}}(\mathrm{x}) \omega^{2} \cos \varphi_{\mathrm{T}}(\mathrm{x})-\mathrm{e}_{\mathrm{T}}(\mathrm{x}) \varepsilon \sin \varphi_{\mathrm{T}}(\mathrm{x})\right] \mathrm{S}(\mathrm{x}) \rho \mathrm{dx}- \\
& -\int_{0}^{\mathrm{L}} \delta \mathrm{z}(\mathrm{x})\left[\ddot{\mathrm{z}}(\mathrm{x})-\mathrm{e}_{\mathrm{T}}(\mathrm{x}) \omega^{2} \sin \varphi_{\mathrm{T}}(\mathrm{x})+\mathrm{e}_{\mathrm{T}}(\mathrm{x}) \varepsilon \cos \varphi_{\mathrm{T}}(\mathrm{x})\right] \mathrm{S}(\mathrm{x}) \rho \mathrm{dx}- \\
& -\int_{0}^{\mathrm{L}} \delta \varphi_{\mathrm{y}}(\mathrm{x})\left[\mathrm{J}_{\mathrm{SD}}(\mathrm{x}) \ddot{\varphi}_{\mathrm{y}}(\mathrm{x})+\mathrm{J}_{\mathrm{SP}}(\mathrm{x}) \omega \dot{\varphi}_{\mathrm{z}}(\mathrm{x})+\mathrm{J}_{\mathrm{SP}}(\mathrm{x}) \varepsilon \varphi_{\mathrm{z}}(\mathrm{x})\right] \rho \mathrm{dx}- \\
& -\int_{0}^{\mathrm{L}} \delta \varphi_{\mathrm{z}}(\mathrm{x})\left[\mathrm{J}_{\mathrm{SD}}(\mathrm{x}) \ddot{\varphi}_{\mathrm{z}}(\mathrm{x})-\mathrm{J}_{\mathrm{SP}}(\mathrm{x}) \omega \dot{\varphi}_{\mathrm{y}}(\mathrm{x})-\mathrm{J}_{\mathrm{SP}}(\mathrm{x}) \varepsilon \varphi_{\mathrm{y}}(\mathrm{x})\right] \rho \mathrm{dx}
\end{aligned}
$$

After expressing the virtual displacements and rotations in a matrix form

$$
\begin{aligned}
& \delta \mathrm{y}(\mathrm{x})=\delta \mathbf{x}_{\mathrm{HE}}^{\mathrm{T}} \mathbf{P}^{-1 \mathrm{~T}} \mathbf{p}_{\mathrm{y}}(\mathrm{x}) \\
& \delta \mathrm{z}(\mathrm{x})=\delta \mathbf{x}_{\mathrm{HE}}^{\mathrm{T}} \mathbf{P}^{-1 \mathrm{~T}} \mathbf{p}_{\mathrm{z}}(\mathrm{x}) \\
& \delta \varphi_{\mathrm{y}}(\mathrm{x})=-\delta \mathbf{x}_{\mathrm{HE}}^{\mathrm{T}} \mathbf{P}^{-1 \mathrm{~T}} \mathbf{r}_{\mathrm{z}}(\mathrm{x}) \\
& \delta \varphi_{\mathrm{z}}(\mathrm{x})=\delta \mathbf{x}_{\mathrm{HE}}^{\mathrm{T}} \mathbf{P}^{-1 \mathrm{~T}} \mathbf{r}_{\mathrm{y}}(\mathrm{x})
\end{aligned}
$$

relationship (39) for the virtual work of inertia effects can be rewritten

$$
\begin{aligned}
\delta \mathrm{A}_{\mathrm{IF}}= & -\delta \mathbf{x}_{\mathrm{HE}}^{\mathrm{T}} \quad \mathbf{P}^{-1 \mathrm{~T}} \int_{0}^{\mathrm{L}} \mathrm{S}(\mathrm{x}) \rho\left[\mathbf{p}_{\mathrm{y}}(\mathrm{x}) \mathbf{p}_{\mathrm{y}}^{\mathrm{T}}(\mathrm{x})+\mathbf{p}_{\mathrm{z}}(\mathrm{x}) \mathbf{p}_{\mathrm{z}}^{\mathrm{T}}(\mathrm{x})\right] \mathrm{dx} \mathbf{P}^{-1} \ddot{\mathbf{x}}_{\mathrm{HE}}^{\mathrm{T}}+ \\
& +\delta \mathbf{x}_{\mathrm{HE}}^{\mathrm{T}} \omega^{2} \mathbf{P}^{-1 \mathrm{~T}} \int_{0}^{\mathrm{L}} \rho \mathrm{S}(\mathrm{x}) \mathrm{e}_{\mathrm{T}}(\mathrm{x})\left[\mathbf{p}_{\mathrm{y}}(\mathrm{x}) \cos \varphi_{\mathrm{T}}(\mathrm{x})+\mathbf{p}_{\mathrm{z}}(\mathrm{x}) \sin \varphi_{\mathrm{T}}(\mathrm{x})\right] \mathrm{dx}- \\
& -\delta \mathbf{x}_{\mathrm{HE}}^{\mathrm{T}} \varepsilon \mathbf{P}^{-1 \mathrm{~T}} \int_{0}^{\mathrm{L}} \rho \mathrm{S}(\mathrm{x}) \mathrm{e}_{\mathrm{T}}(\mathrm{x})\left[-\mathbf{p}_{\mathrm{y}}(\mathrm{x}) \sin \varphi_{\mathrm{T}}(\mathrm{x})+\mathbf{p}_{\mathrm{z}}(\mathrm{x}) \cos \varphi_{\mathrm{T}}(\mathrm{x})\right] \mathrm{dx}- \\
& -\delta \mathbf{x}_{\mathrm{HE}}^{\mathrm{T}} \quad \mathbf{P}^{-1 \mathrm{~T}} \int_{0}^{\mathrm{L}} \rho \mathrm{J}_{\mathrm{SD}}(\mathrm{x})\left[\mathbf{r}_{\mathrm{z}}(\mathrm{x}) \mathbf{r}_{\mathrm{z}}^{\mathrm{T}}(\mathrm{x})+\mathbf{r}_{\mathrm{y}}(\mathrm{x}) \mathbf{r}_{\mathrm{y}}^{\mathrm{T}}(\mathrm{x})\right] \mathrm{dx} \mathbf{P}^{-1} \ddot{\mathbf{x}}_{\mathrm{HE}}- \\
& -\delta \mathbf{x}_{\mathrm{HE}}^{\mathrm{T}} \omega \mathbf{P}^{-1 \mathrm{~T}} \int_{0}^{\mathrm{L}} \rho J_{\mathrm{SP}}(\mathrm{x})\left[-\mathbf{r}_{\mathrm{z}}(\mathrm{x}) \mathbf{r}_{\mathrm{y}}^{\mathrm{T}}(\mathrm{x})+\mathbf{r}_{\mathrm{y}}(\mathrm{x}) \mathbf{r}_{\mathrm{z}}^{\mathrm{T}}(\mathrm{x})\right] \mathrm{dx} \mathbf{P}^{-1} \dot{\mathbf{x}}_{\mathrm{HE}}- \\
& -\delta \mathbf{x}_{\mathrm{HE}}^{\mathrm{T}} \varepsilon \mathbf{P}^{-1 \mathrm{~T}} \int_{0}^{\mathrm{L}} \rho \mathrm{J}_{\mathrm{SP}}(\mathrm{x})\left[-\mathbf{r}_{\mathrm{z}}(\mathrm{x}) \mathbf{r}_{\mathrm{y}}^{\mathrm{T}}(\mathrm{x})+\mathbf{r}_{\mathrm{y}}(\mathrm{x}) \mathbf{r}_{\mathrm{z}}^{\mathrm{T}}(\mathrm{x})\right] \mathrm{dx} \mathbf{P}^{-1} \mathbf{x}_{\mathrm{HE}}
\end{aligned}
$$

After performing the integrations the relation for the virtual work $\delta \mathrm{A}_{\mathrm{IF}}$ takes a simple form

$$
\delta \mathrm{A}_{\mathrm{IF}}=-\delta \mathbf{x}_{\mathrm{HE}}^{\mathrm{T}}\left[\left(\mathbf{M}_{\mathrm{HE}} \ddot{\mathbf{x}}_{\mathrm{HE}}+\omega \mathbf{G}_{\mathrm{HE}} \dot{\mathbf{x}}_{\mathrm{HE}}+\varepsilon \mathbf{G}_{\mathrm{HE}} \mathbf{x}_{\mathrm{HE}}\right)-\mathbf{f}_{\mathrm{HEUN}}-\mathbf{f}_{\mathrm{HEUT}}\right]
$$

where 


$$
\begin{gathered}
\mathbf{M}_{\mathrm{HE}}=\mathbf{P}^{-1 \mathrm{~T}} \int_{0}^{\mathrm{L}} \rho\left[S(\mathrm{x}) \mathbf{Y}_{1}(\mathrm{x})+\mathrm{J}_{\mathrm{SD}}(\mathrm{x}) \mathbf{Y}_{2}(\mathrm{x})\right] \mathrm{dx} \mathbf{P}^{-1} \\
\mathbf{G}_{\mathrm{HE}}=\mathbf{P}^{-1 \mathrm{~T}} \int_{0}^{\mathrm{L}} \rho \mathrm{J}_{\mathrm{SP}}(\mathrm{x}) \mathbf{Y}_{3}(\mathrm{x}) \mathrm{dx} \mathbf{P}^{-1} \\
\mathbf{f}_{\mathrm{HEUN}}=\omega^{2} \mathbf{P}^{-1 \mathrm{~T}} \int_{0}^{\mathrm{L}} \rho \mathrm{S}(\mathrm{x}) \mathrm{e}_{\mathrm{T}}(\mathrm{x})\left[\mathbf{p}_{\mathrm{y}}(\mathrm{x}) \cos \varphi_{\mathrm{T}}(\mathrm{x})+\mathbf{p}_{\mathrm{z}}(\mathrm{x}) \sin \varphi_{\mathrm{T}}(\mathrm{x})\right] \mathrm{dx} \\
\mathbf{f}_{\mathrm{HEUT}}=\varepsilon \mathbf{P}^{-1 \mathrm{~T}} \int_{0}^{\mathrm{L}} \rho \mathrm{S}(\mathrm{x}) \mathrm{e}_{\mathrm{T}}(\mathrm{x})\left[\mathbf{p}_{\mathrm{y}}(\mathrm{x}) \sin \varphi_{\mathrm{T}}(\mathrm{x})-\mathbf{p}_{\mathrm{z}}(\mathrm{x}) \cos \varphi_{\mathrm{T}}(\mathrm{x})\right] \mathrm{dx}
\end{gathered}
$$

and

$$
\begin{aligned}
& \mathbf{Y}_{1}(\mathrm{x})=\mathbf{p}_{\mathrm{y}}(\mathrm{x}) \mathbf{p}_{\mathrm{y}}^{\mathrm{T}}(\mathrm{x})+\mathbf{p}_{\mathrm{z}}(\mathrm{x}) \mathbf{p}_{\mathrm{z}}^{\mathrm{T}}(\mathrm{x}) \\
& \mathbf{Y}_{2}(\mathrm{x})=\mathbf{r}_{\mathrm{y}}(\mathrm{x}) \mathbf{r}_{\mathrm{y}}^{\mathrm{T}}(\mathrm{x})+\mathbf{r}_{\mathrm{z}}(\mathrm{x}) \mathbf{r}_{\mathrm{z}}^{\mathrm{T}}(\mathrm{x}) \\
& \mathbf{Y}_{3}(\mathrm{x})=-\mathbf{r}_{\mathrm{z}}(\mathrm{x}) \mathbf{r}_{\mathrm{y}}^{\mathrm{T}}(\mathrm{x})+\mathbf{r}_{\mathrm{y}}(\mathrm{x}) \mathbf{r}_{\mathrm{z}}^{\mathrm{T}}(\mathrm{x})
\end{aligned}
$$

$\mathbf{M}_{\mathrm{HE}}$ and $\mathbf{G}_{\mathrm{HE}}$ are the mass and gyroscopic matrices of the shaft finite element, $\mathbf{f}_{\mathrm{HE}}$ is the vector of applied forces acting on the liberated element, and $\mathbf{f}_{\text {HEUN }}$ and $\mathbf{f}_{\text {HEUT }}$ are the vectors of the normal (centrifugal) and tangential components of the distributed inertia force acting on the element due to its unbalance.

According to the principle of virtual work substituting (30) and (45) into (29) and some simple manipulations give

$$
\mathbf{M}_{\mathrm{HE}} \ddot{\mathbf{x}}_{\mathrm{HE}}+\left(\mathbf{B}_{\mathrm{HE}}+\eta_{\mathrm{v}} \mathbf{K}_{\mathrm{HE}}+\omega \mathbf{G}_{\mathrm{HE}}\right) \dot{\mathbf{x}}_{\mathrm{HE}}+\left(\mathbf{K}_{\mathrm{HE}}+\omega \mathbf{K}_{\mathrm{CHE}}+\varepsilon \mathbf{G}_{\mathrm{HE}}\right) \mathbf{x}_{\mathrm{HE}}=\mathbf{f}_{\mathrm{HE}}+\mathbf{f}_{\mathrm{HEUN}}+\mathbf{f}_{\mathrm{HEUT}}
$$

\section{The equation of motion of the rotor system}

In the mathematical model (i) the shaft is represented by a beam - like body that is discretized into shaft finite elements, (ii) the discs are thin and rigid bodies, (iii) the material of the shaft and of the stationary part is linear and isotropic, (iv) the rolling-element bearings are implemented into the mathematical model by linear spring and dashpot elements, (v) the external and material damping is considered to be linear, (vi) the rotor turns in time, varying the speed of the known time history, and it is assumed that (vii) amplitude of its vibration is small.

The equation of motion of the total rotor system is derived from the equations of motion of its individual elements (shaft elements, discs)

$$
\mathbf{M} \ddot{\mathbf{x}}+\left(\mathbf{B}+\eta_{\mathrm{V}} \mathbf{K}_{\mathrm{SH}}+\omega \mathbf{G}\right) \dot{\mathbf{x}}+\left(\mathbf{K}+\omega \mathbf{K}_{\mathrm{C}}+\varepsilon \mathbf{G}\right) \mathbf{x}=\mathbf{f}_{\mathrm{A}}+\mathbf{f}_{\mathrm{C}}
$$

where $\mathbf{M}, \mathbf{B}, \mathbf{K}, \mathbf{G}, \mathbf{K}_{\mathrm{C}}$ are the mass, damping, stiffness, gyroscopic, and circulation matrices, $\mathbf{K}_{\mathrm{SH}}$ is the stiffness matrix of the shaft, $\mathbf{f}_{\mathrm{A}}, \mathbf{f}_{\mathrm{C}}$ are the vectors of applied and constraint forces, $\mathbf{x}, \dot{\mathbf{x}}, \ddot{\mathbf{x}}$ are the vectors of general displacements, velocities, and accelerations of the rotor system, and $\eta_{V}$ is the coefficient of viscous damping of the shaft material. 
Matrix $\mathbf{B}$ defines the external damping of the shaft and material and external damping of the stationary part. To set it up several approaches have been developed and they can be found in a number of publications (proportional damping, Rayleigh damping, etc.).

To solve the equation of motion (54) the Newmark method is proposed. This method is implicit and it implies it starts from the equation of motion related to time $t+\Delta t$. To calculate new kinematic parameters its algorithm requires to set up the effective stiffness matrix $\mathbf{K}_{\mathrm{ef}, t+\Delta t}$

$$
\mathbf{K}_{\mathrm{ef}, \mathrm{t}+\Delta \mathrm{t}}=\mathbf{K}+\omega \mathbf{K}_{\mathrm{C}}+\varepsilon \mathbf{G}+\frac{1}{\beta \Delta \mathrm{t}^{2}} \mathbf{M}+\frac{\gamma}{\beta \Delta \mathrm{t}}\left(\mathbf{B}+\eta_{\mathrm{V}} \mathbf{K}_{\mathrm{SH}}+\omega \mathbf{G}\right)
$$

and the right-hand side vector $\mathbf{f}_{\mathrm{ef}, \mathrm{t}+\Delta \mathrm{t}}$ [25-27] and to solve a set of linear algebraic equations at each integration step to obtain new values of the system displacements

$$
\mathbf{K}_{\text {ef }, \mathrm{t}+\Delta \mathrm{t}} \mathbf{x}_{\mathrm{t}+\Delta \mathrm{t}}=\mathbf{f}_{\mathrm{ef}, \mathrm{t}+\Delta \mathrm{t}}
$$

$\beta, \gamma$ are coefficients of the Newmark method and $\Delta t$ is the time step. It is worth to note that the coefficient matrix $\mathbf{K}_{\mathrm{ef}, t+\Delta \mathrm{t}}$ changes due to variable angular speed $\omega$, acceleration $\varepsilon$, and stiffness of the supports (matrix $\mathbf{K}$ ) during the investigated period. Therefore, it is necessary to set it up and to perform its elimination, if the Gauss method is applied for its solution, repeatedly at each integration step.

Calculation of the system eigenvalues $\lambda$ arrives at solving a quadratic eigenvalue problem

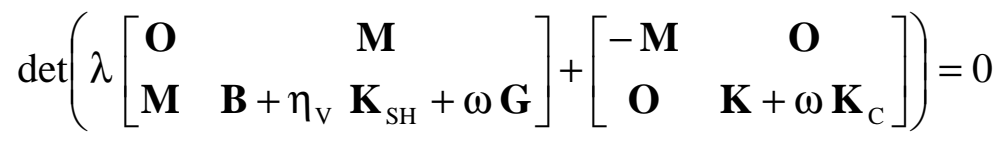

$\mathbf{O}$ is a zero matrix. Equation (57) holds only for the operating conditions when the rotor rotates at a constant angular speed.

\section{Example}

The applicability of the described approach was tested by means of computer simulations. The rotor of the investigated rotor system (Fig.5) consists of a shaft SH and of three discs D1, $\mathrm{D} 2$, D3. The shaft is mounted with the bearing housings $\mathrm{BH} 1, \mathrm{BH} 2$ by two rolling element bearings B1, B2. The bearing housings are coupled with the rigid foundation plate FP by springs of controllable stiffness and by damping elements. The rotor rotates at a constant angular speed of $200 \mathrm{rad} / \mathrm{s}$. At a specified moment of time it starts to accelerate uniformly and when reaching the velocity of $600 \mathrm{rad} / \mathrm{s}$ it continues in rotation with a constant angular speed. The rotor is loaded by its weight and is excited by centrifugal forces caused by the unbalances of all discs. Design parameters of the system are summarized in the Appendix.

The task was to analyze the attenuation of lateral vibration of the rotor when it increases the angular velocity of its rotation and passes over the critical speeds by means of frequency tuning. This manipulation is accomplished by a change in the stiffness of the bearing housing supports. Some results of the performed simulations are evident from the following figures. 


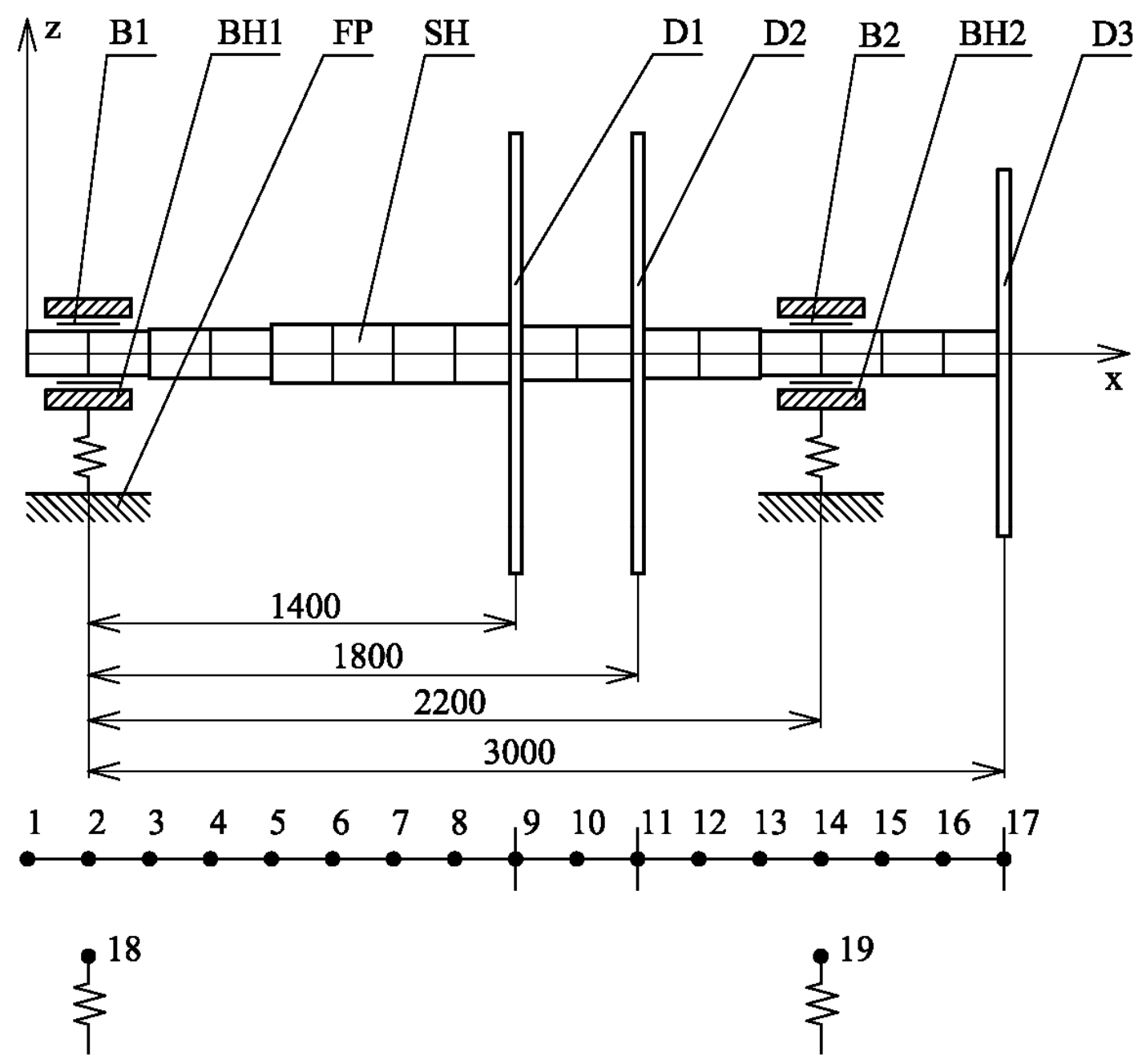

Fig.5 Scheme of the investigated rotor system

The dependence of the damped natural frequencies of the rotor on the speed of its rotation is expressed by the Campbell diagram drawn in Fig.6. It is evident that the rotor must pass two critical rotational speeds $(291.5 \mathrm{rad} / \mathrm{s}, 469.8 \mathrm{rad} / \mathrm{s})$ during its acceleration. This is confirmed also by the frequency characteristic related to the vertical vibration of the disc D3 centre in Fig.7. Dependence of the amplitude of the force transmitted from the rotor into the foundation plate in a vertical direction at locations of bearing housings $\mathrm{BH} 1$ and $\mathrm{BH} 2$ can be seen in Fig.8 and 9. 


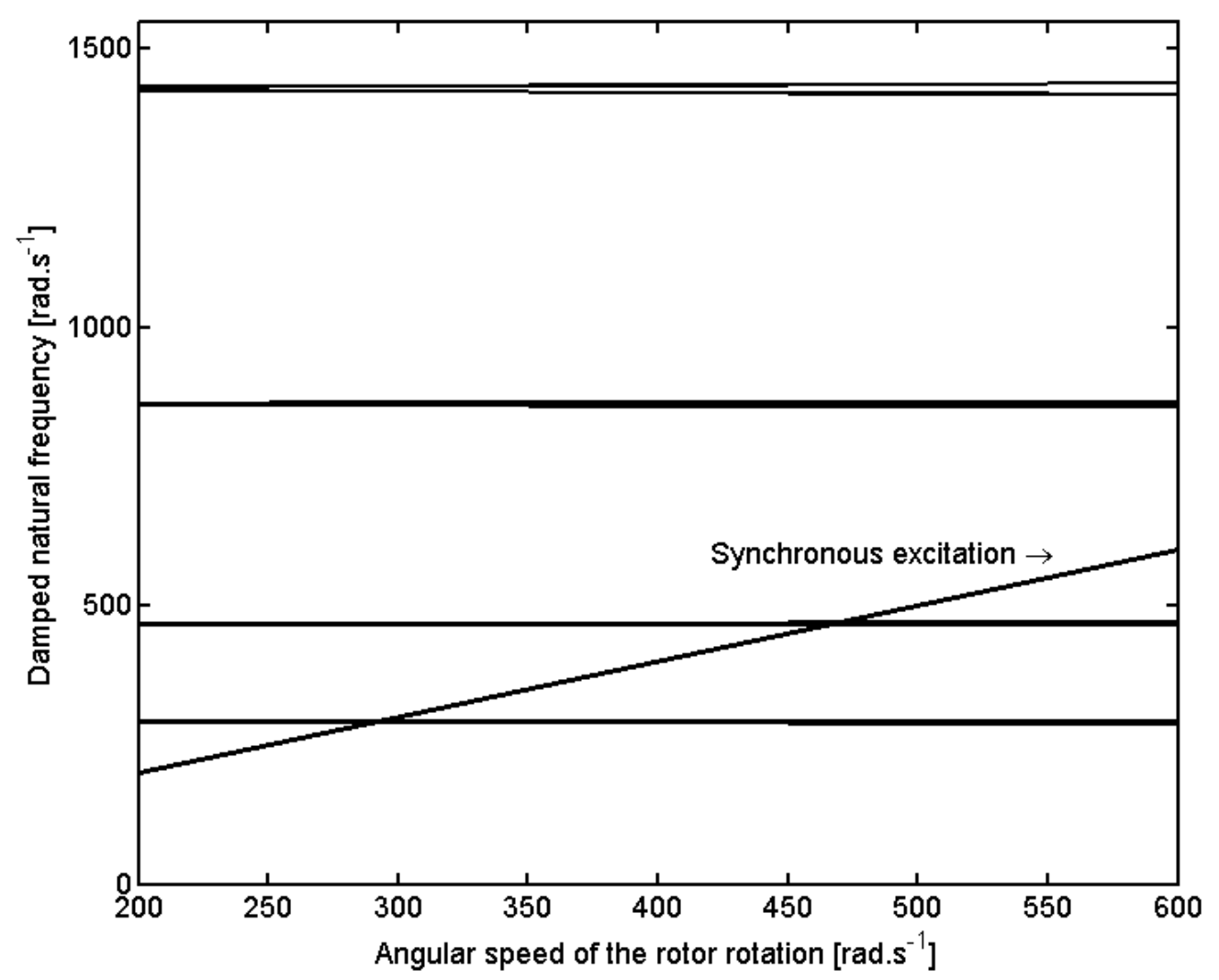

Fig.6 Campbell diagram

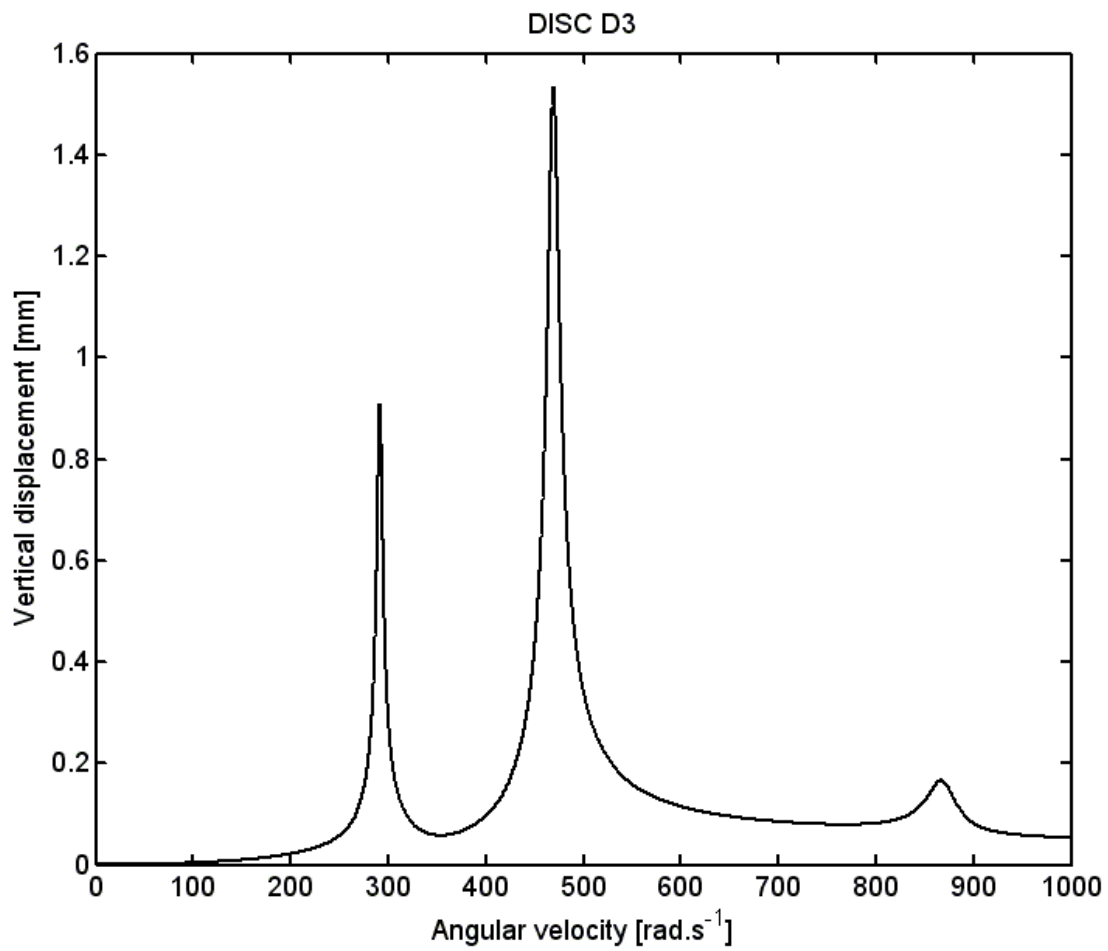

Fig.7 Frequency characteristics - amplitude of the vertical displacement of disc D3 


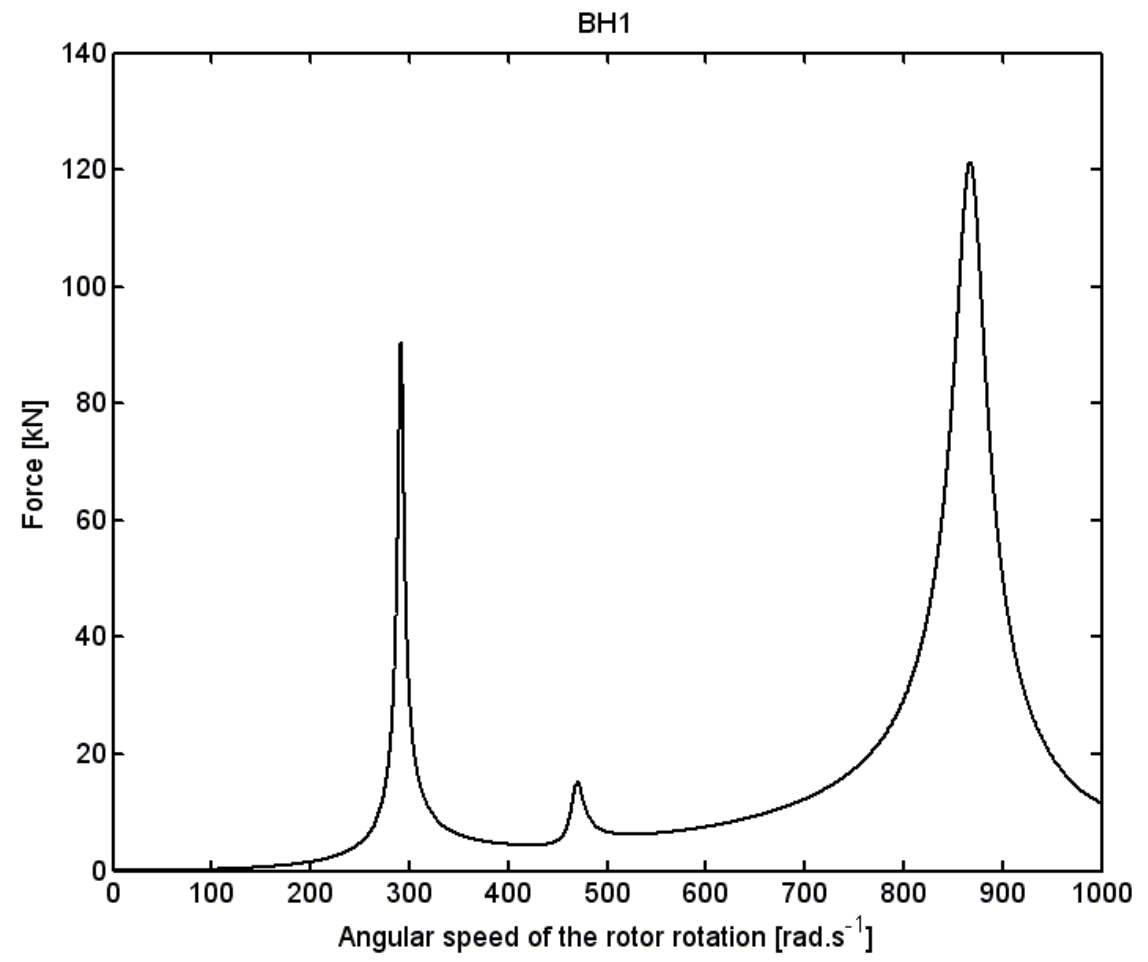

Fig. 8 Force transmitted into the foundations - the speed of the rotor rotation relationship at bearing housing $\mathrm{BH} 1$

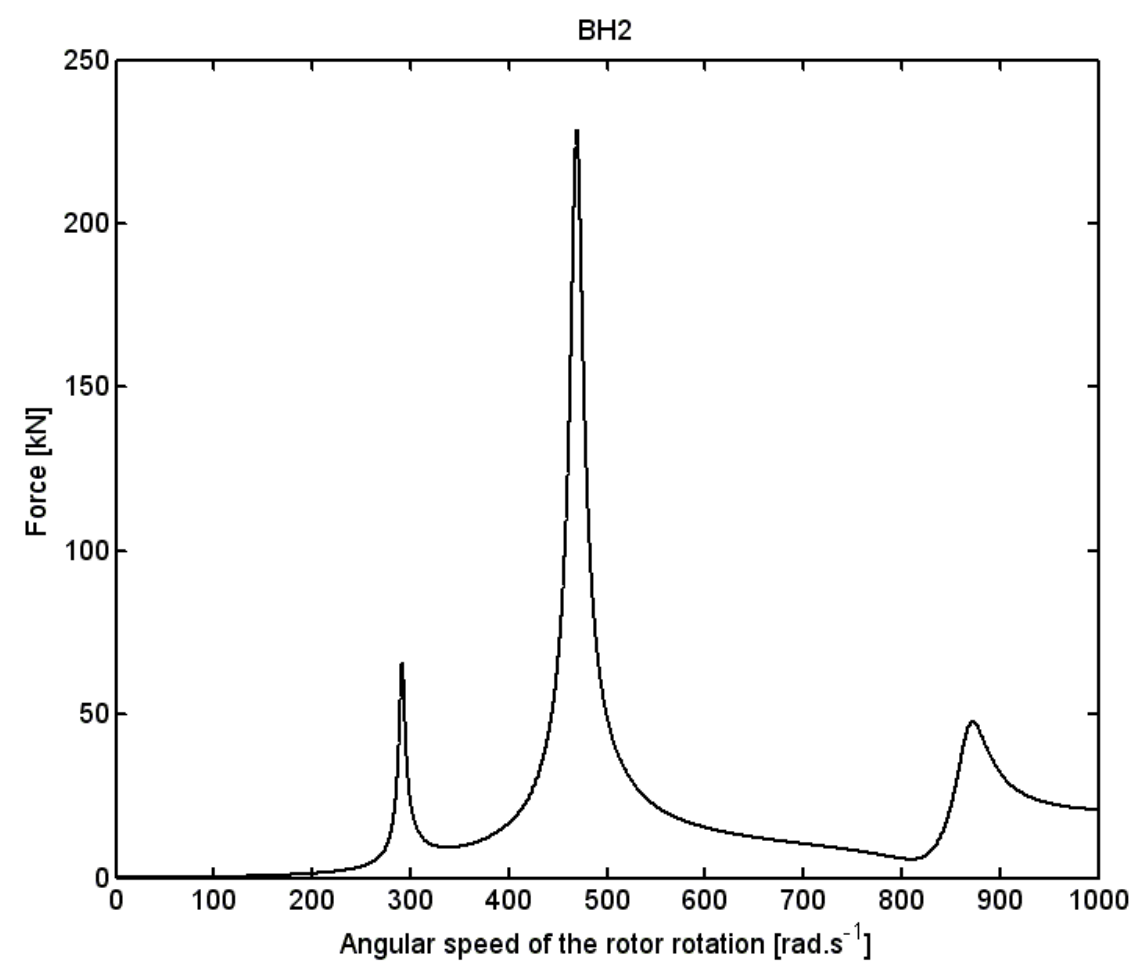

Fig.9 Force transmitted into the foundations - the speed of the rotor rotation relationship at bearing housing $\mathrm{BH} 2$ 


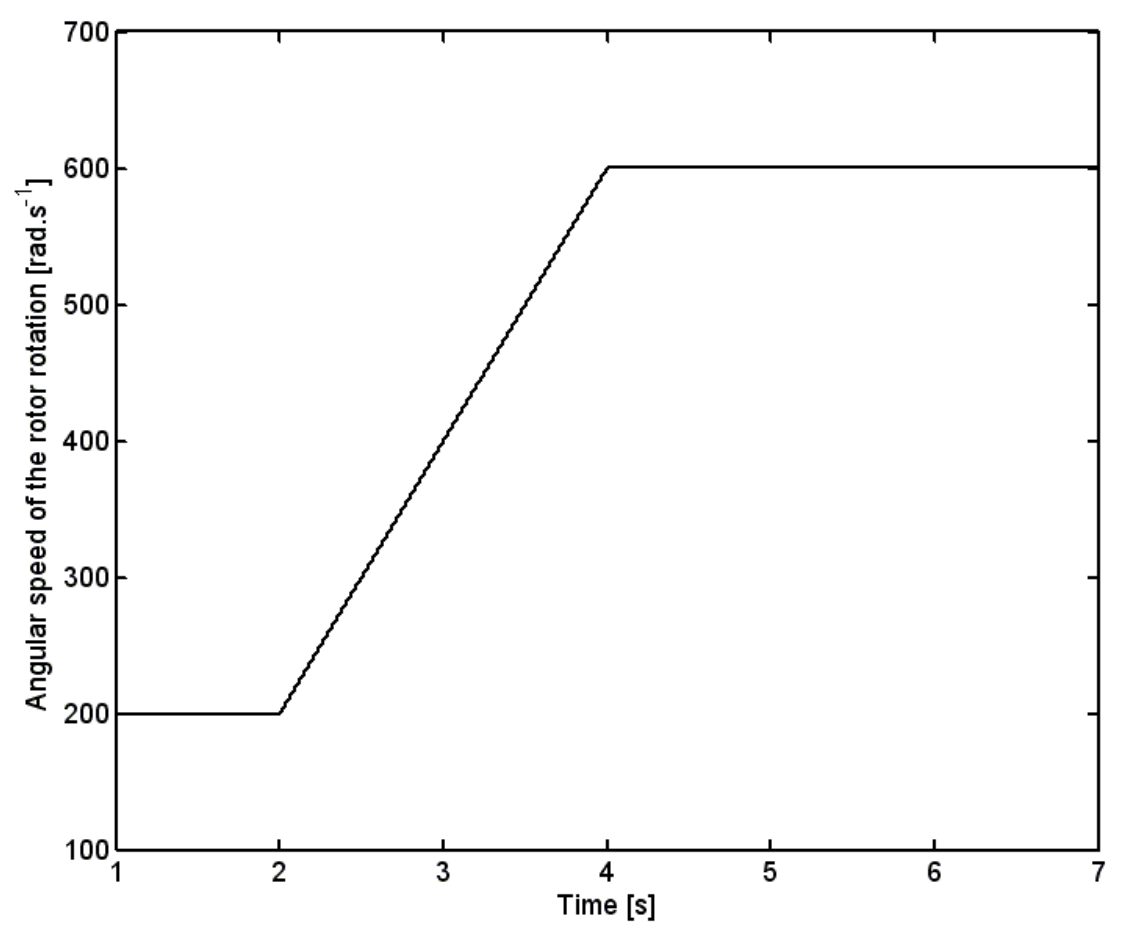

Fig.10 Time history of velocity of the rotor rotation

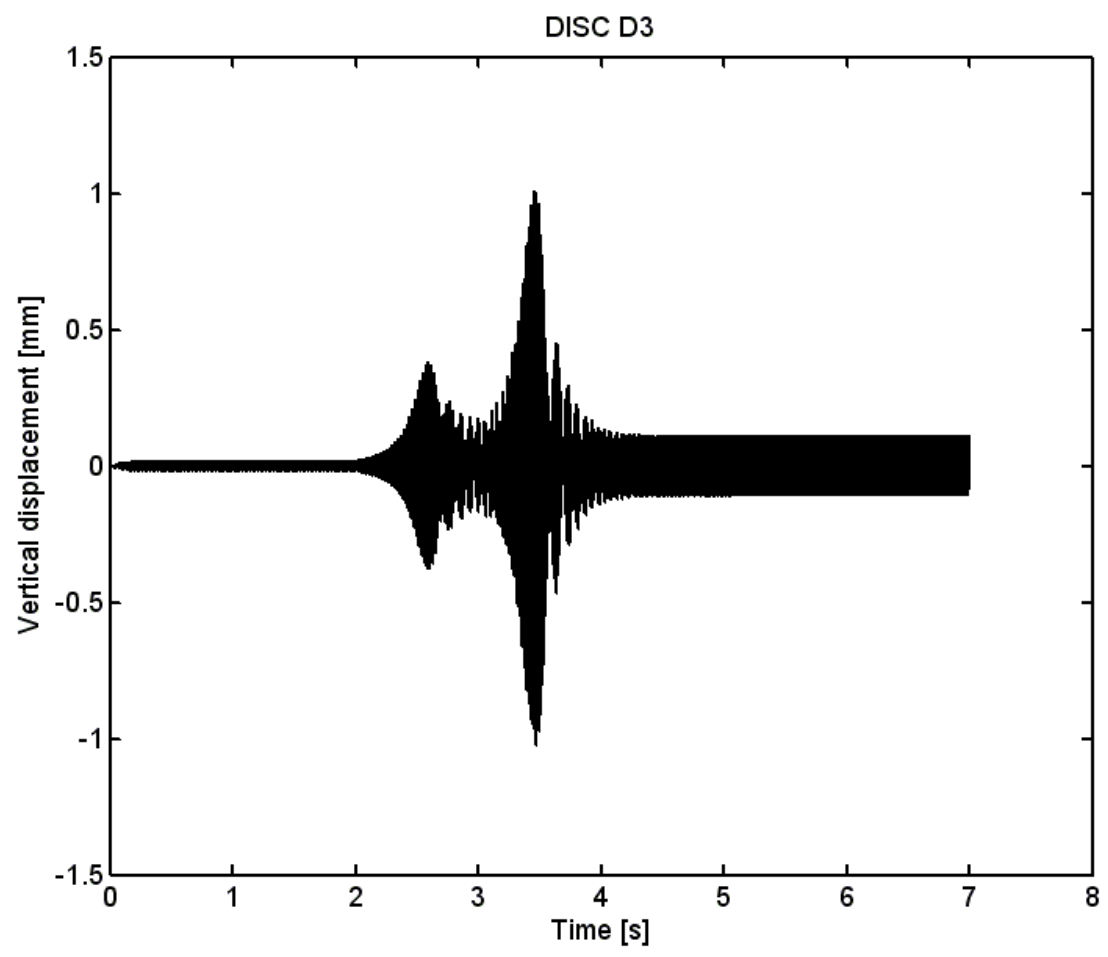

Fig.11 Displacement of disc D3 in the vertical direction (without frequency tuning) 


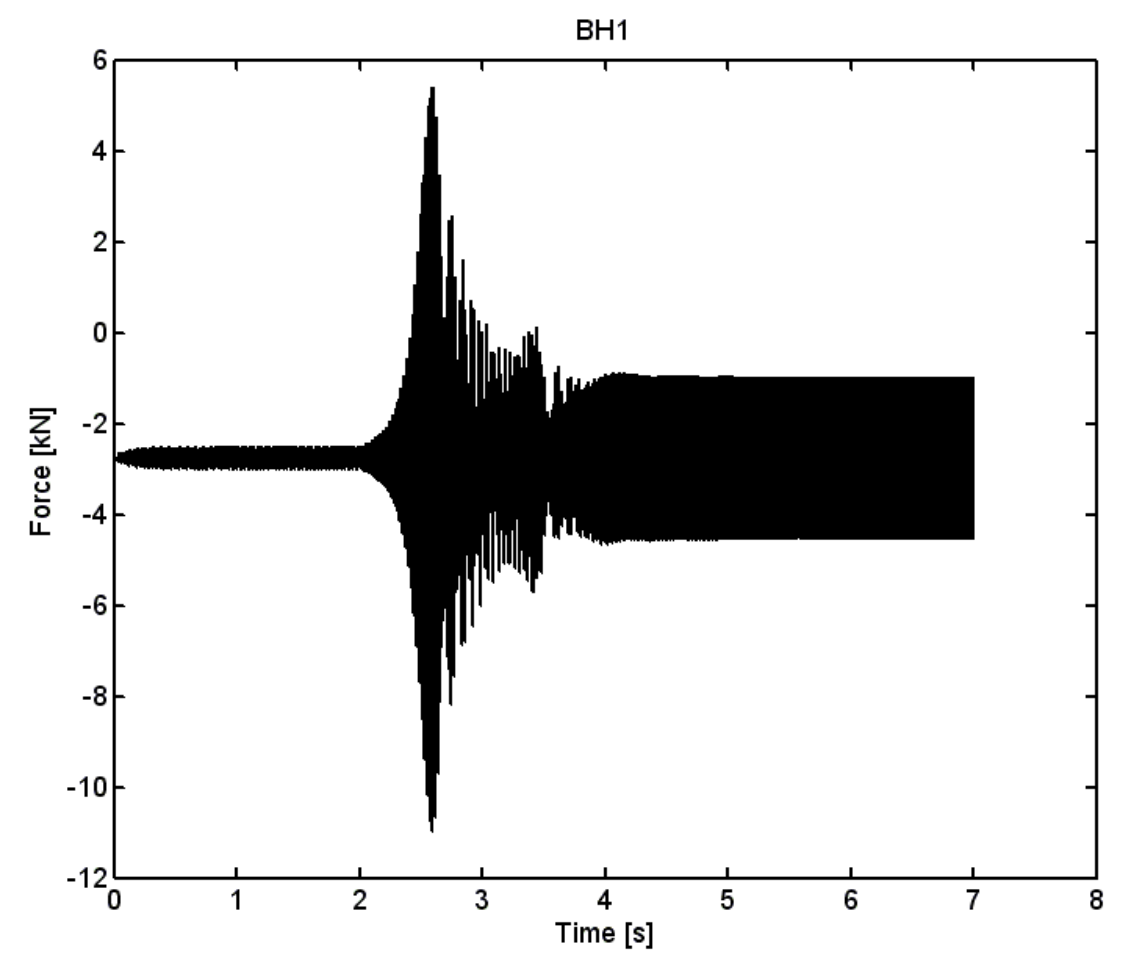

Fig.12 The force transmission between the bearing housing $\mathrm{BH} 1$ and the foundation plate (without frequency tuning)

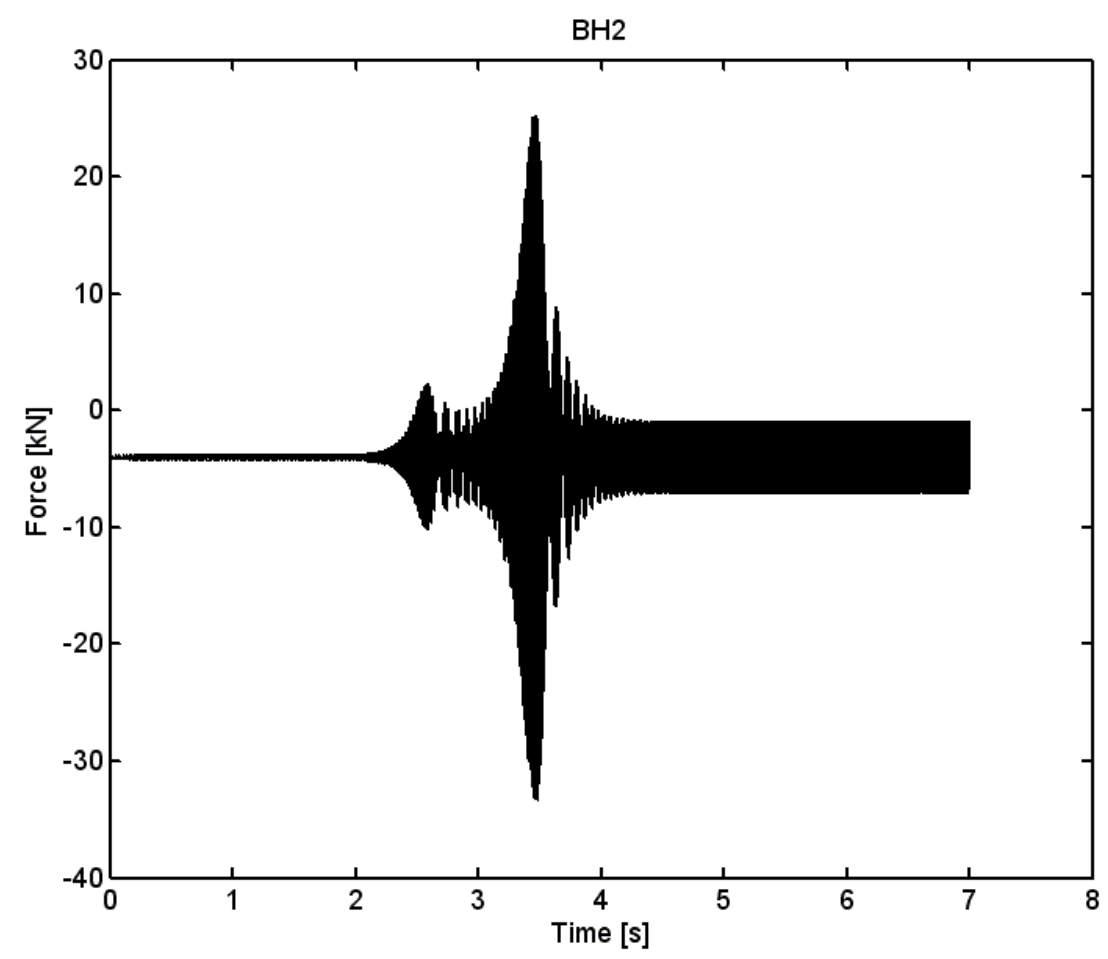

Fig.13 The force transmission between the bearing housing $\mathrm{BH} 2$ and the foundation plate (without frequency tuning) 


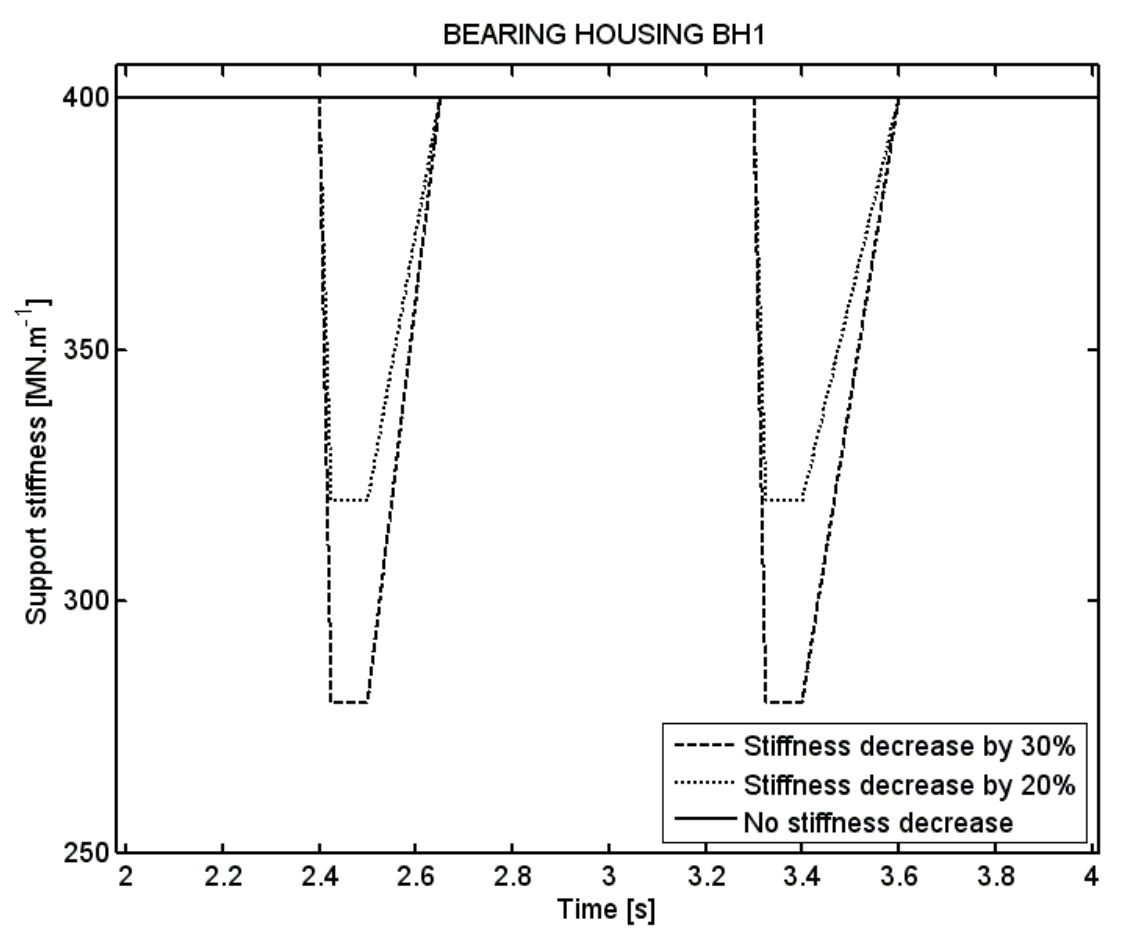

Fig.14 Time history in the stiffness of the bearing housing supporting springs

The force peaks appear at the frequencies corresponding to the critical revolutions of the rotor. Fig.10 shows the time history of velocity of the rotor rotation before, during, and after its acceleration. The time history of displacement of disc D3 in the vertical direction and the force transmitted between the bearing housings $\mathrm{BH} 1$ and $\mathrm{BH} 2$ and the foundation plate without the frequency tuning are drawn in Fig.11, 12 and 13. At the moments of time when the rotor passes the first and second critical revolutions the amplitude of the disc vibration and magnitude of the forces transmitted into the foundations rise sharply. The time history of the drop and consequent increase in the stiffness of the bearing housing supporting springs in the vertical and horizontal directions depending on the rotor revolutions are evident from Fig.14. This manipulation starts when the rotor reaches $96 \%$ of its critical speed and is finished when the speed exceeds critical revolutions by about $13 \%$. The results of the same analysis (time history of the displacement of the disc D3 centre, forces transmitted between the rotor and its foundations) but when the frequency tuning accomplished by the decrease in the stiffness of the shaft supports by $20 \%$ and $30 \%$ is switched on can be seen in Fig.15-20. Comparing Fig. 11, 15 and 18 it is evident that the maximum amplitude of disc D3 vibration is lowered by $15 \%$ and $26 \%$ when the rotor runs over the second critical revolution. But when it passes the first critical speed this operation has only a little effect on its vibration. An influence in the change in stiffness of the bearing housing $\mathrm{BH} 2$ supports on the force transmitted into the foundation plate in the vertical direction is significant if the rotor runs over the second critical revolution. As evident from Fig.13, 17, 20 and especially from Fig.21 its magnitude is lowered about 1.5 times. This occurs also if the rotor passes the first critical revolution but the force reduction is smaller. The effect of the frequency tuning on the force transmission between the rotor and the foundation plate at the location of bearing housing BH1 is not very significant (Fig.12, 16, 19, and 22). But the magnitude of this force is about 5 times lower than that of the force transmitted into the foundations at the location of bearing housing $\mathrm{BH} 2$. 


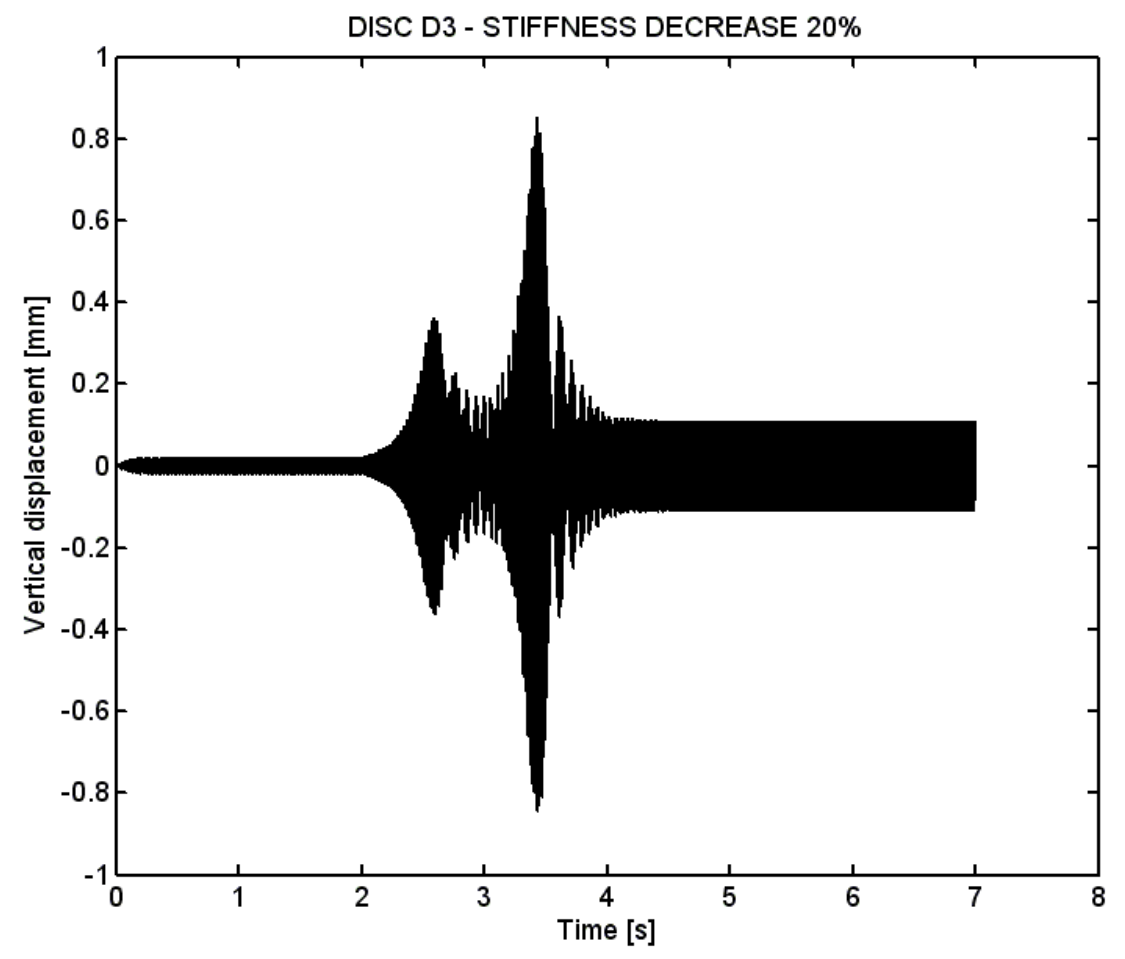

Fig.15 Displacement of disc D3 in the vertical direction (stiffness decrease 20\%)

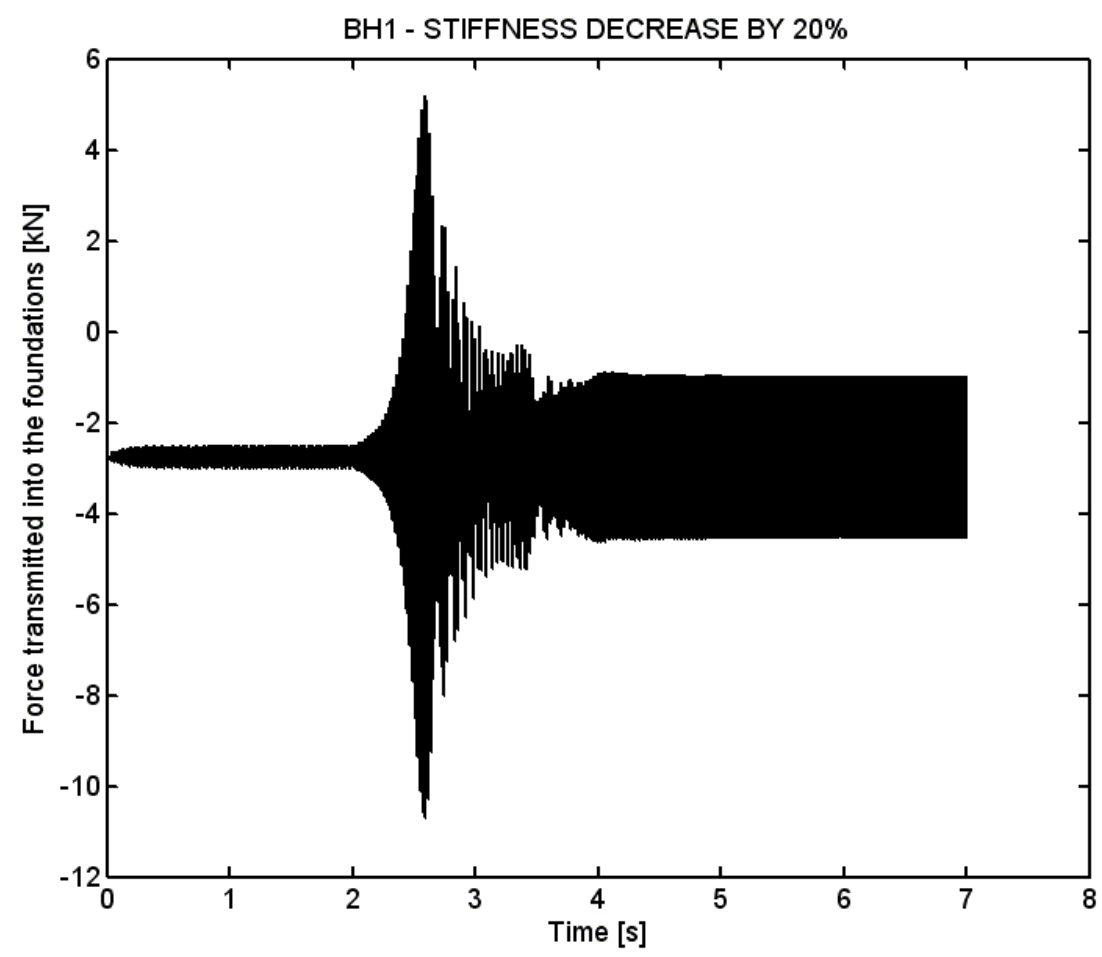

Fig.16 The force transmission between the bearing housing BH1 and the foundation plate (stiffness decrease 20\%) 


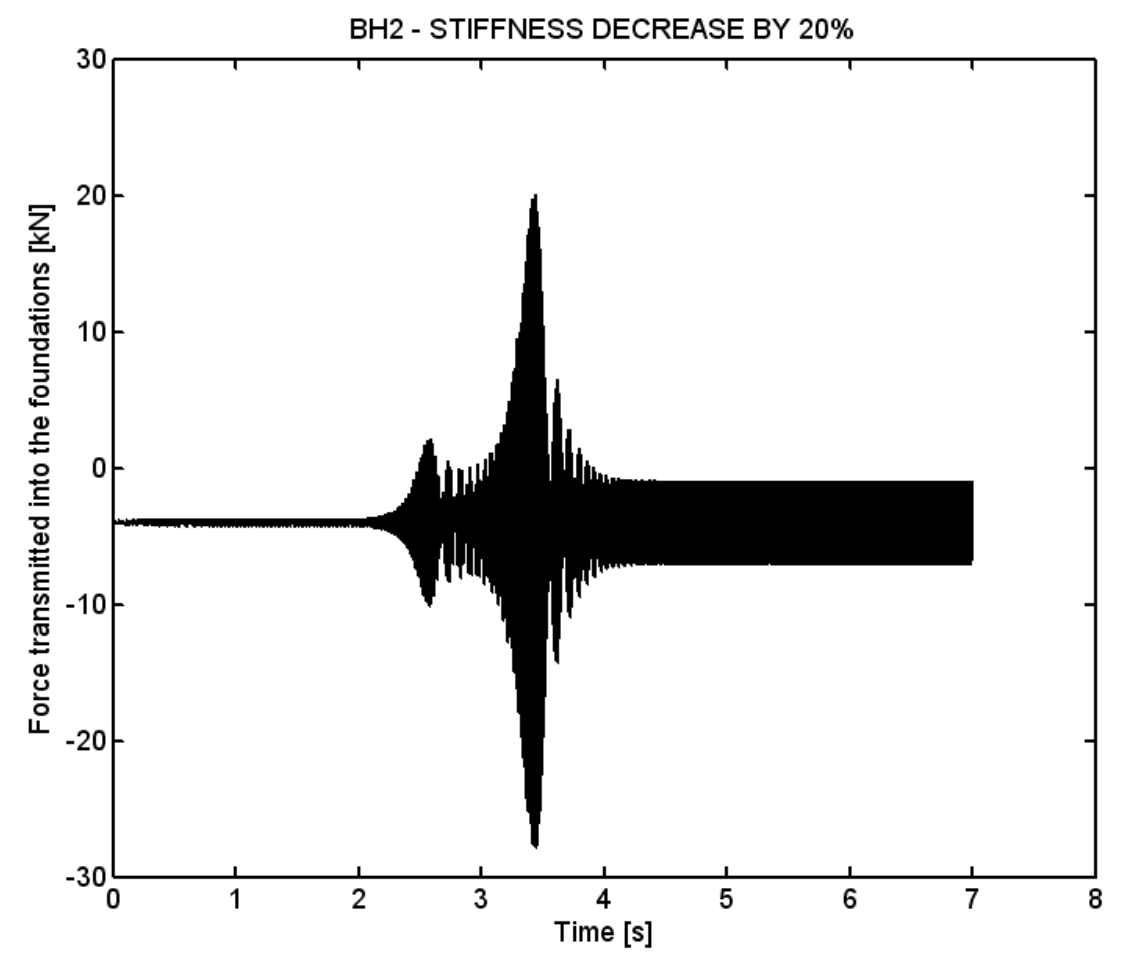

Fig.17 The force transmission between the bearing housing $\mathrm{BH} 2$ and the foundation plate (stiffness decrease 20\%)

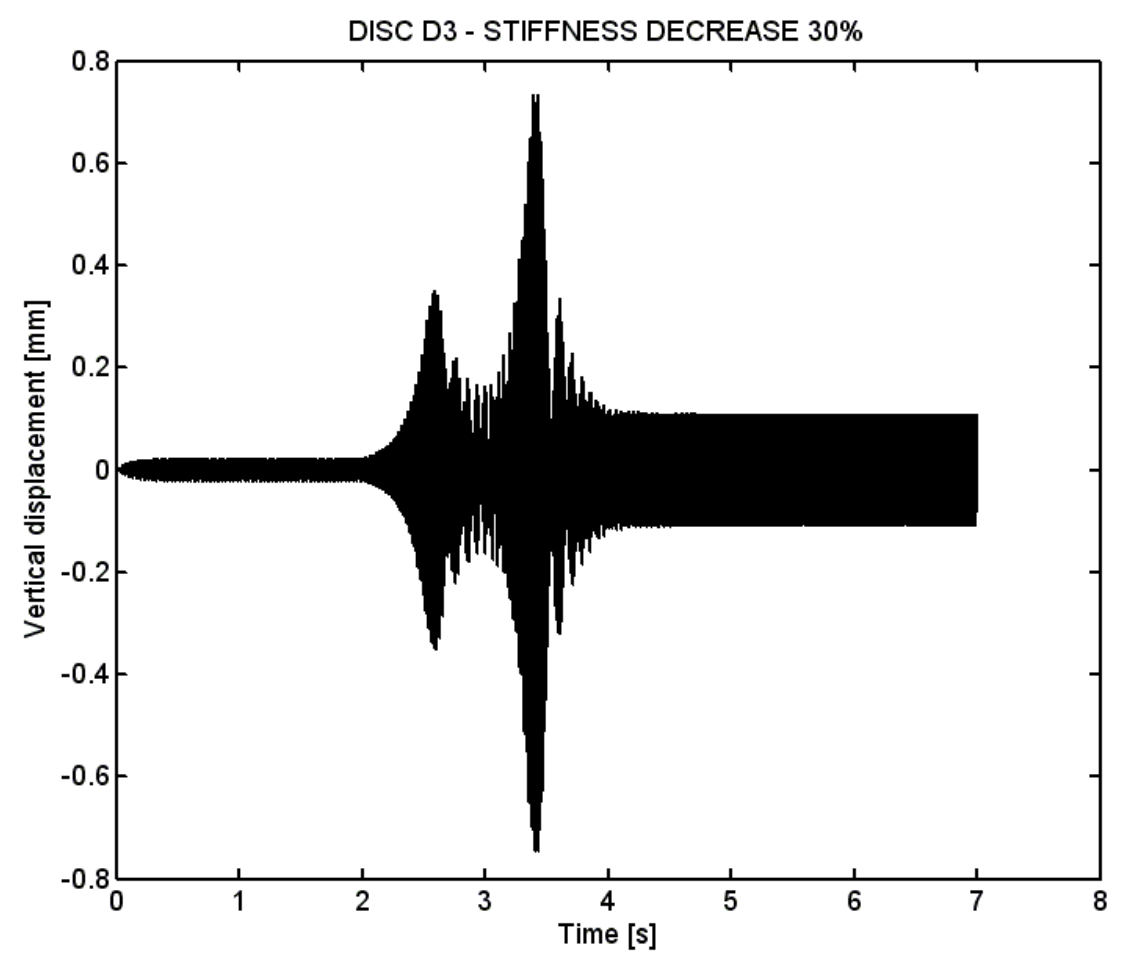

Fig.18 Displacement of disc D3 in the vertical direction (stiffness decrease 30\%) 


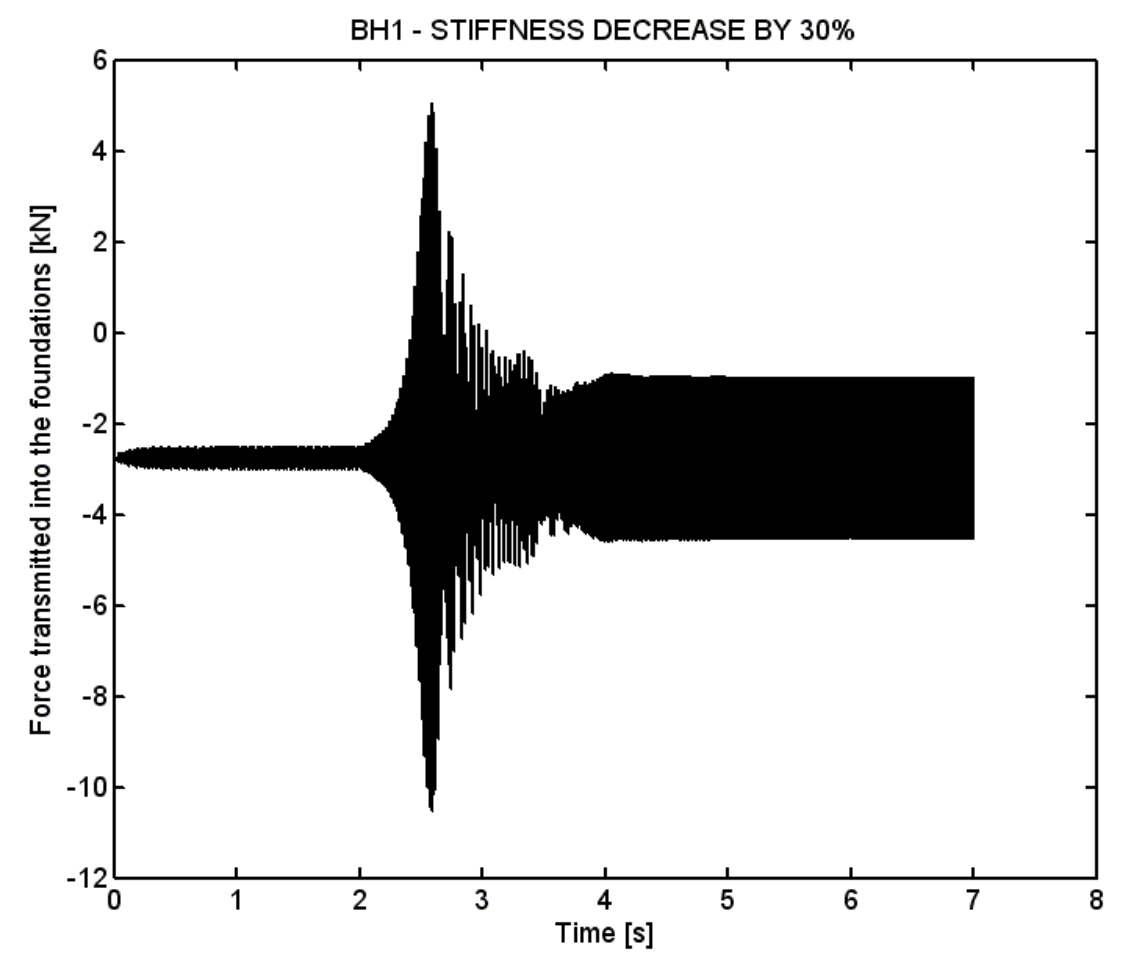

Fig.19 The force transmission between the bearing housing BH1 and the foundation plate (stiffness decrease 30\%)

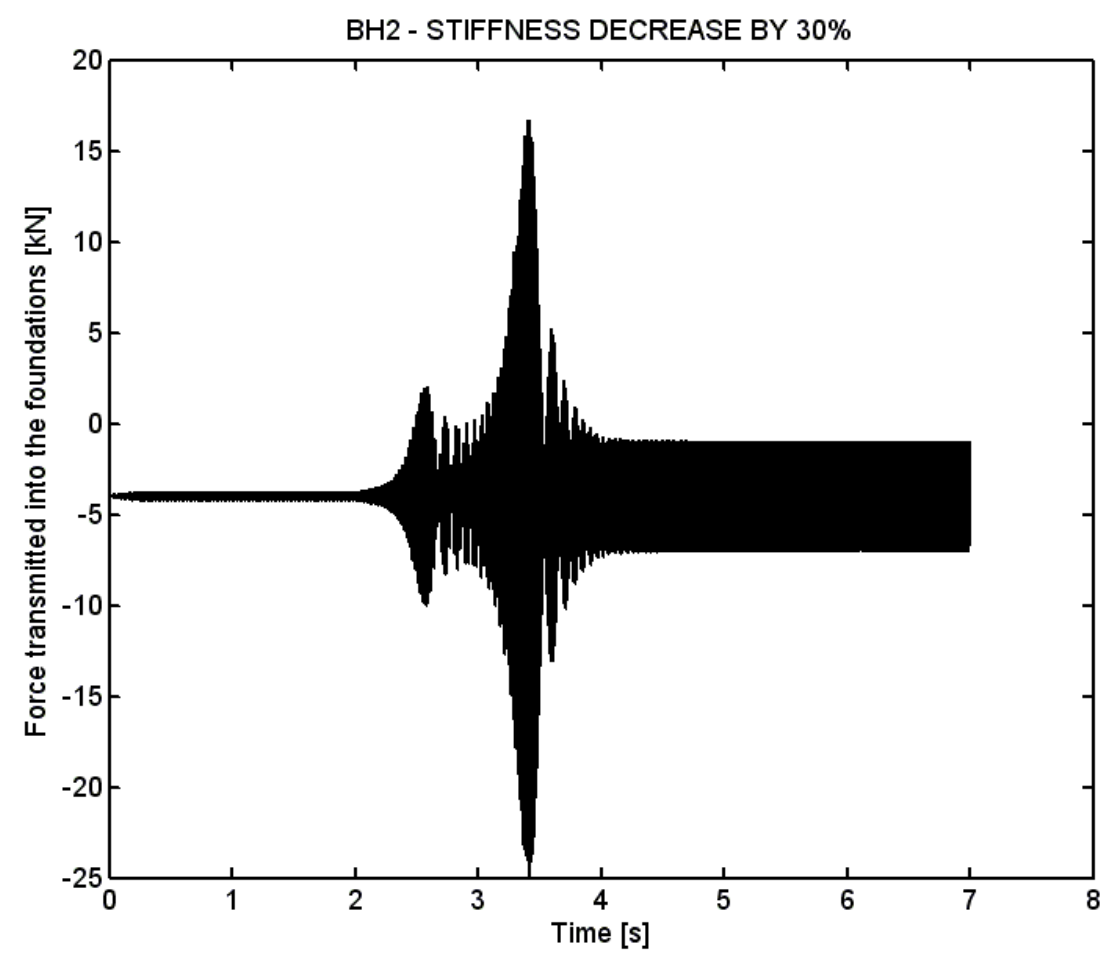

Fig.20 The force transmission between the bearing housing $\mathrm{BH} 2$ and the foundation plate (stiffness decrease 30\%) 


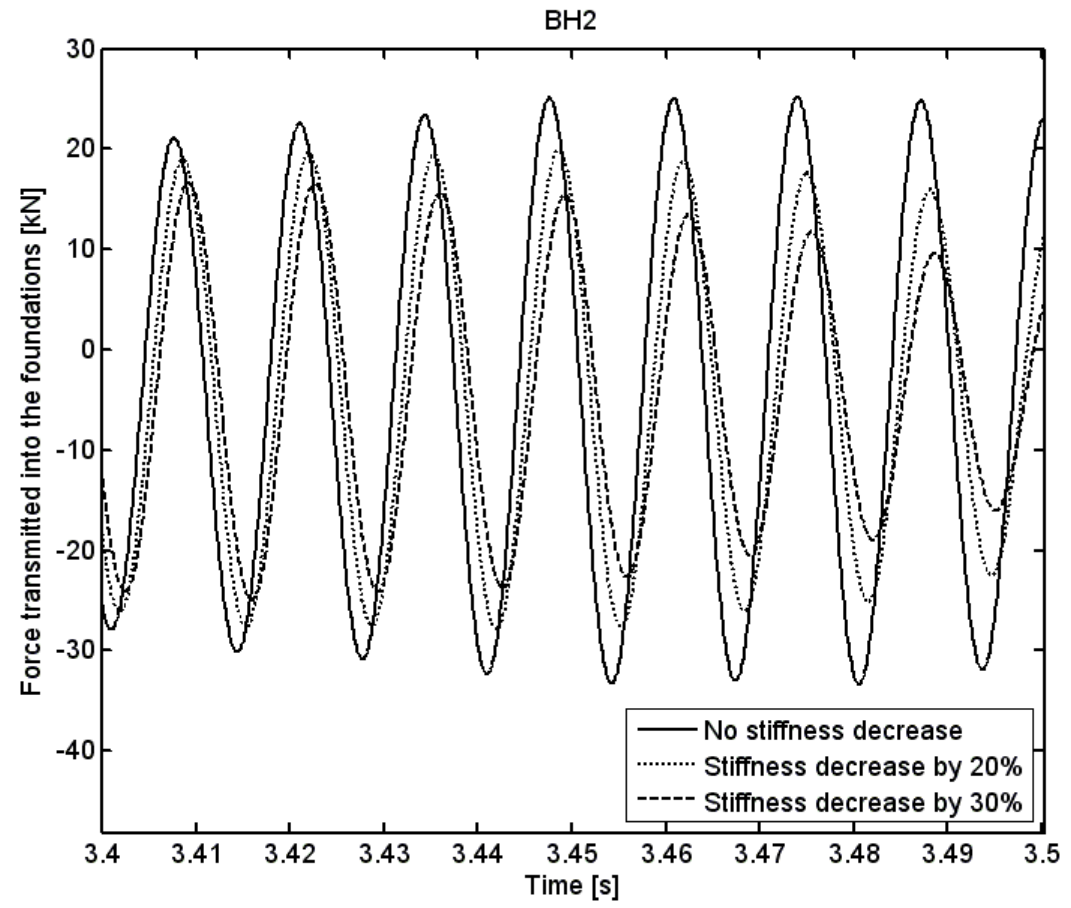

Fig.21 The force transmission between the bearing housing $\mathrm{BH} 2$ and the foundation plate during passage of the rotor over the second critical revolutions

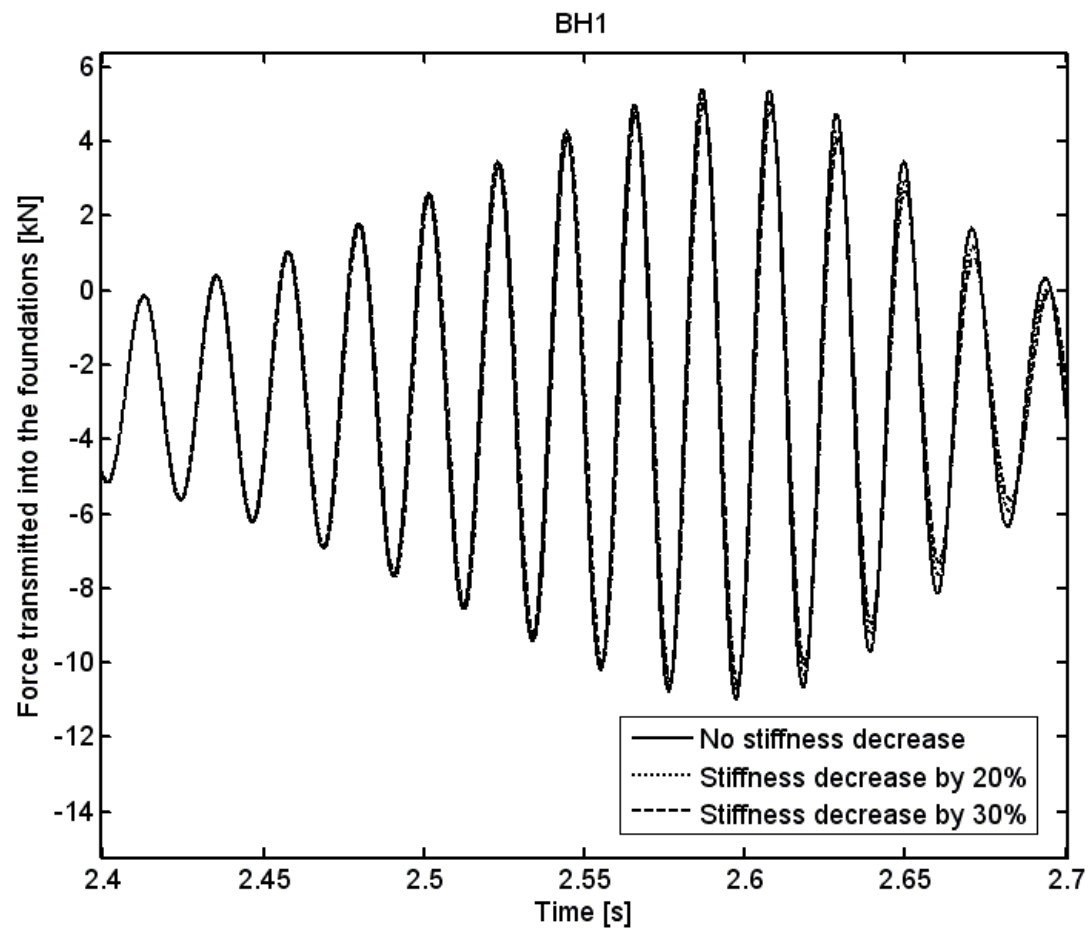

Fig.22 The force transmission between the bearing housing $\mathrm{BH} 1$ and the foundation plate during passage of the rotor over the first critical revolutions 
The attenuation of lateral vibration of accelerating rotors passing critical speeds is an important technological problem. One possibility of its solution consists in controlling the frequency tuning of the rotor system. The stiffness of the bearing housings is decreased shortly before the rotor reaches the critical revolutions and after overcoming them it rises again. The principal goals of this operation are the reduction of stress and the deformation of the shaft and the possibility of applying a driving motor of a lower rated power. Results of the carried out research show that efficiency of this manipulation depends not only on the amount of decrease of the support stiffness, but also on its rate and on moment of time when the tuning started before reaching the critical speed.

For analysis and planning this operating manipulation a computer modelling method can be applied. In the developed procedure the shaft is implemented into the model system by means of a beam-like body that is for the purpose of the further analysis discretized into finite elements. The discs are considered as thin and rigid. The coupling between the bearing housings and the base plate is flexible and its stiffness is controllable which enables a frequency tuning of the system.

The principal contribution of this article consists in the derivation of the equation of motion of a rotor rotating at a time variable angular velocity and the development of a numerical procedure for investigating the attenuation of amplitude of lateral vibration of rotors passing the critical speeds by means of reducing the stiffness of the coupling between the bearing housings and the foundations. To derive the equations of motion the principle of virtual work was used. The d'Alembert forces were determined by means of Lagrange equations of the second kind. The moment equations of motion of discs and rotors in some previous publications differ in terms that take into account the influence of the inertia moment of the spin motion on their lateral vibration. The reason is that these equations are expressed in different reference frames, e.g. after performing the transformation from non-orthogonal to the orthogonal coordinate system in [10] or after the backward transformation from the reference frame coupled to the middle plane of the disc to the fixed coordinate system in [11] the equations of motion take the same form as derived in this article or published in [5-7]. After performing the missing transformations all moment equations of motion take the identical form independent on the method used for their derivation. These additional inertia terms cannot be neglected only because of the assumption of small displacements and rotations because they are of the same magnitude as other elastic, damping, gyroscopic and inertia forces and moments acting on the system. The importance of these terms increases with the rising magnitude of the rotor angular acceleration or deceleration (e.g. in the cases of sudden changes of operating conditions, impacts, etc.). The structure of the resulting equations shows that components of the inertia moment of the spin motion have the same effect on the rotor as internal damping and therefore they influence the stability of the rotor lateral vibration. The moment equations of motion containing the additional inertia terms are compatible with force ones because they also contain terms proportional to angular acceleration of the rotor. Omitting these additional inertia terms in one or in both moment equations changes the mathematical properties of the resulting set of governing equations and affects the method of their solution.

The applicability of the described approach was tested by means of computer simulations. The results showed that efficiency of this technological operation depended on the magnitude of the change of the support stiffness. The developed algorithm behaved numerically stable 
including the cases of a sharp reduction or increase of the rotor supports stiffness. Utilization of this approach can be extended also on a wider scale of technological problems, e.g. when the rotor is loaded by base plate excitation.

\section{Acknowledgement}

This work has been supported by the research projects AVO Z20760514 and P101/10/0209. The support is gratefully acknowledged. 
Geometry of the shaft:

$\begin{array}{llll}\text { Element } & 1 & \text { length } 200 \mathrm{~mm} & \text { diameter } 140 \mathrm{~mm} \\ \text { Element } & 2 & \text { length } 200 \mathrm{~mm} & \text { diameter } 140 \mathrm{~mm} \\ \text { Element } & 3 & \text { length } 200 \mathrm{~mm} & \text { diameter } 160 \mathrm{~mm} \\ \text { Element } & 4 & \text { length } 200 \mathrm{~mm} & \text { diameter } 160 \mathrm{~mm} \\ \text { Element } & 5 & \text { length } 200 \mathrm{~mm} & \text { diameter } 180 \mathrm{~mm} \\ \text { Element } & 6 & \text { length } 200 \mathrm{~mm} & \text { diameter } 180 \mathrm{~mm} \\ \text { Element } & 7 & \text { length } 200 \mathrm{~mm} & \text { diameter } 180 \mathrm{~mm} \\ \text { Element } & 8 & \text { length } 200 \mathrm{~mm} & \text { diameter } 180 \mathrm{~mm} \\ \text { Element } & 9 & \text { length } 200 \mathrm{~mm} & \text { diameter } 160 \mathrm{~mm} \\ \text { Element } & 10 & \text { length } 200 \mathrm{~mm} & \text { diameter } 160 \mathrm{~mm} \\ \text { Element } & 11 & \text { length } 200 \mathrm{~mm} & \text { diameter } 160 \mathrm{~mm} \\ \text { Element } & 12 & \text { length } 200 \mathrm{~mm} & \text { diameter } 160 \mathrm{~mm} \\ \text { Element } & 13 & \text { length } 200 \mathrm{~mm} & \text { diameter } 140 \mathrm{~mm} \\ \text { Element } & 14 & \text { length } 200 \mathrm{~mm} & \text { diameter } 140 \mathrm{~mm} \\ \text { Element } & 15 & \text { length } 200 \mathrm{~mm} & \text { diameter } 140 \mathrm{~mm} \\ \text { Element } & 16 & \text { length } 200 \mathrm{~mm} & \text { diameter } 140 \mathrm{~mm}\end{array}$

Material of the shaft:

Young's modulus

$2.1 \cdot 10^{11} \mathrm{~N} \mathrm{~m}^{-2}$

0.3

Poisson's ratio

Density

Coefficient of viscous damping

Rayleigh coefficient of external damping

$7800 \mathrm{~kg} \mathrm{~m}^{-3}$

$2.0 \cdot 10^{-7} \mathrm{~s}$

$5 \mathrm{~s}^{-1}$

(related to the mass matrix)

Parameters of the discs:

Disc D1: mass

diameter moment of inertia

axial moment of inertia

unbalance

$24 \mathrm{~kg}$

$0.09 \mathrm{~kg} \mathrm{~m}^{2}$

$0.18 \mathrm{~kg} \mathrm{~m}^{2}$

$2.4 \mathrm{~kg} \mathrm{~mm}$

Disc D2: mass

$32 \mathrm{~kg}$

diameter moment of inertia

axial moment of inertia

$0.12 \mathrm{~kg} \mathrm{~m}^{2}$

$0.24 \mathrm{~kg} \mathrm{~m}^{2}$

unbalance

$6.4 \mathrm{~kg} \mathrm{~mm}$

Disc D3: mass

$32 \mathrm{~kg}$

diameter moment of inertia

axial moment of inertia

$0.12 \mathrm{~kg} \mathrm{~m}^{2}$

unbalance

$0.24 \mathrm{~kg} \mathrm{~m}^{2}$

$3.2 \mathrm{~kg} \mathrm{~mm}$

Parameters of the bearings:

Stiffness

Damping

$1.0 \cdot 10^{8} \mathrm{~N} \mathrm{~m}^{-1}$

$10 \mathrm{~kg} \mathrm{~s}^{-1}$

Parameters of the bearing housings:

Stiffness

Damping

Mass

$40.0 \cdot 10^{7} \mathrm{~N} \mathrm{~m}^{-1}$

$1.0 \cdot 10^{5} \mathrm{~kg} \mathrm{~s}^{-1}$

$55 \mathrm{~kg}$ 


\section{References}

[1] M.A. Franchek, M.W. Ryan, R.J. Bernard, Adaptive passive vibration control, Journal of Sound and Vibration. 189 (1995) 565-585.

[2] A. Blanco-Ortega, G. Silva-Navarro, J.C. Gómez-Mancilla, Active vibration control on a rotor-bearing system using hybrid journal bearings, Proceedings of the 12th International Congress on Sound and Vibration (2005).

[3] K. Nagaya, S. Takeda, Y. Tsukui, T. Kumaido, Active control method for passing through critical speeds of rotating shafts by changing stiffness of the supports with use of memory metals, Journal of Sound and Vibration. 113 (1987) 307-315.

[4] T. Yamamoto, Y. Ishida, Linear and nonlinear rotordynamics. A modern treatment with applications, John Wiley \& Sons Ltd., New York, 2001.

[5] R. Gasch, R. Nordmann, H. Pfützner, Rotordynamik, Springer, Berlin, Heidelberg, 2002 (in German).

[6] Y. Ishida, K. Yasuda, S. Murakami, Nonstationary oscillation of a rotating shaft with nonlinear spring characteristics during acceleration through a major critical speed (A discussion by the asymptotic method and the complex-FFT method), ASME Journal of Vibration and Acoustics. 119 (1997) 31-36.

[7] Y. Ishida, T. Yamamoto, S. Murakami, Nonstationary vibration of a rotating shaft with nonlinear spring characteristics during acceleration through a critical speed (A critical speed of a 1/3-order subharmonic oscillation), JSME International Journal Series III. 35 (1992) 360-368.

[8] Y. Ishida, T. Yamamoto, T. Ikeda, S. Murakami, Nonstationary vibration of a rotating shaft with nonlinear spring characteristics during acceleration through a critical speed (A critical speed of a summed-and-differential harmonic oscillation), Nonlinear Dynamics. 1 (1990) 341-358.

[9] Y. Ishida, T. Ikeda, T. Yamamoto, Transient vibration of a rotating shaft with nonlinear spring characteristics during acceleration through a major critical speed, JSME International Journal. 30 (1987) 458-466.

[10] M. Lalanne, G. Ferraris, Rotordynamics prediction in engineering, John Wiley Sons, Chichester, 1990.

[11] G. Genta, Dynamics of rotating systems, Springer, New York, 2005.

[12] A. Blanco-Ortega, G. Silva-Navarro, J.C. Gómez-Mancilla, Dynamic stiffness control and acceleration scheduling for the active balancing control of a Jeffcott-like rotor, Proceedings of the 10th International Congress on Sound and Vibration (2003).

[13] H.D. Nelson, J.M. McVaugh, The dynamics of rotor-bearing systems using finite elements, ASME Journal of Engineering for Industry. 98 (1976) 593-600.

[14] J. Zapoměl, Computer modelling of lateral vibration of rotors supported by hydrodynamic bearings and squeeze film dampers, VSB - Technical university of Ostrava, Ostrava, 2007 (in Czech).

[15] E.S. Zorzi, H.D. Nelson, Finite element simulation of rotor-bearing systems with internal damping, ASME Journal of Engineering for Power. 99 (1977) 71-76.

[16] E. Krämer, Dynamics of Rotors and Foundations, Springer-Verlag, Berlin, 1993.

[17] H. Irretier, F. Leul, Nonstationary vibrations of mechanical systems with slowly varying natural frequencies during acceleration through resonance, Proceedings of the 9th IFToMM World Congress on the Theory of Machines and Mechanisms (1995).

[18] I. Ballo, R. Chmúrny, Passage of the flexible slender rotor through critical speed, Proceedings of the Engineering Mechanics 2003 (2003), CD 1-9 (in Slovak). 
[19] I. Ballo, R. Chmúrny, Optimization of the parameters at the passage of the rotor through critical speed by means of proper tuning, Proceedings of the Engineering Mechanics 2004, (2004), CD 1-6 (in Slovak).

[20] I. Ballo, R. Chmurny, Critical speed passage of a flexible slender rotor by re-tuning, Journal of Mechanical Engineering. 58 (2007) 216-227.

[21] J. Wauer, S. Suherman, Vibration suppression of rotating shafts passing through resonances by switching shaft stiffness, ASME Journal of Vibration and Acoustics. (120) 1998 170-180.

[22] K.T. Millsaps, G.L. Reed, Reducing lateral vibrations of a rotor passing through critical speeds by acceleration scheduling, Journal for Engineering for Gas Turbines and Power. 120 (1998) 615-620.

[23] J. Kiciński, Rotor dynamics, Institute of Fluid Flow Machinery, Gdaňsk, 2006.

[24] D. Childs, Turbomachinery Rotordynamics. Phenomena, Modeling, and Analysis, John Wiley \& Sons Ltd., New York, 1993.

[25] K. Subbaraj, M.A. Dokainish, A survey of direct time-integration methods in computational structural dynamics - II. implicit methods, Computers \& Structures. 32 (1989) 1387-1401.

[26] K.J. Bathe, Finite element procedures, Prentice Hall, Inc., New Jersey, 1996.

[27] K.J. Bathe, E.L Wilson, Numerical methods in finite element analysis, Prentice Hall, Inc., New Jersey, 1976. 